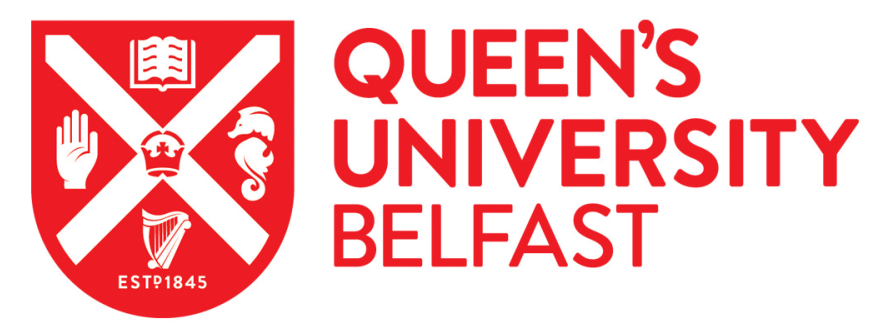

\title{
Creating loops with value recovery: empirical study of fresh food supply chains
}

Vlajic, J. V., Mijailovic, R., \& Bogdanova, M. (2018). Creating loops with value recovery: empirical study of fresh food supply chains. Production Planning \& Control: The Management of Operations, 29(6), 522-538. https://doi.org/10.1080/09537287.2018.1449264

Published in:

Production Planning \& Control: The Management of Operations

Document Version:

Peer reviewed version

Queen's University Belfast - Research Portal:

Link to publication record in Queen's University Belfast Research Portal

Publisher rights

(C) 2017 Informa UK Limited, trading as Taylor \& Francis Group.

This work is made available online in accordance with the publisher's policies. Please refer to any applicable terms of use of the publisher.

\section{General rights}

Copyright for the publications made accessible via the Queen's University Belfast Research Portal is retained by the author(s) and / or other copyright owners and it is a condition of accessing these publications that users recognise and abide by the legal requirements associated with these rights.

Take down policy

The Research Portal is Queen's institutional repository that provides access to Queen's research output. Every effort has been made to ensure that content in the Research Portal does not infringe any person's rights, or applicable UK laws. If you discover content in the Research Portal that you believe breaches copyright or violates any law, please contact openaccess@qub.ac.uk. 


\section{Creating loops with value recovery: empirical study of fresh food}

supply chains

Jelena V. Vlajic ${ }^{\mathrm{a}^{*}}$, Radomir Mijailovic ${ }^{\mathrm{b}}$, Mariana Bogdanova ${ }^{\mathrm{c}}$,

${ }^{a}$ Queen's Management School, Queens University Belfast, Belfast, UK,

+44 (0) 289097 4804, email: j.vlajic@qub.ac.uk

${ }^{b}$ University of Belgrade - The Faculty of Transport and Traffic Engineering, Belgrade, Serbia,

+381(0) 113091 381, email: radomirm@sf.bg.ac.rs

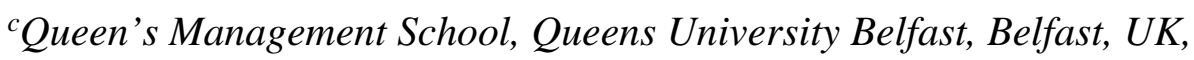

+ 44 (0)289097 4719, email: m.bogdanova@qub.ac.uk

*Corresponding author. Email: j.vlajic@qub.ac.uk 


\section{Creating loops with value recovery: empirical study of fresh food supply chains}

In an era of increased scarcity of resources and pollution, the concept of the circular economy is re-emerging to steer supply chains towards more sustainable business practices. The potential of value recovery provides opportunities for the creation of circular supply chains. Reverse flows and value recovery processes are scarcely studied in the context of fresh food supply chains. In this paper, we report findings from an empirical study of three food networks regarding the nature of circular flows, as well as factors that affect their creation. These networks differ in their structure and organisation of value recovery processes. We analyse value recovery in light of following elements: product residual value, quantities available for recovery, value from recovery, and markets for recovered products. We show that 1) financial value from recovery is a necessary condition for profitability of operations of any value recovery process in fresh food supply chains, but not for the occurrence of the corresponding loop itself; 2) reuse and remanufacturing loops likely feed into alternative markets, while recycling loops likely feed back into fresh food supply chains.

Keywords: circular flows; reuse, remanufacture and recycle; small and medium companies. 


\section{Introduction}

The concept of the circular economy has deep roots in several disciplines and cannot be traced back to one single author or date (Webster, 2015). However, the majority of studies on the circular economy refer to Boulding's ideas on the economy and the environment as closed systems, where "the outputs of all parts of the system are linked to the inputs of other parts", and inputs and outputs consist of matter, energy and information (Boulding, 1966, 1). Since then, these ideas (Lieder and Rashid, 2016) have been refined in the context of the functional service economy (Stahel, 2006), cradle-tocradle flows (Braungart and McDonough, 2009), industrial ecology (Geng and Doberstein, 2008) and industrial symbiosis (Chertow, 2007).

In recent studies, the circular economy "refers to an industrial economy that is restorative by intention", (Webster, 2015, 52). Webster explains that the concept of circular economy is grounded in the study of non-linear, living systems, where the main notion is to optimise systems rather than its components. In optimising systems, it is important to distinguish biological and man-made systems: 1) biological materials (renewables) are returned to nature after production and consumption, and 2) technical materials (man-made materials) are returned to the supply chain, but not to nature (Braungart and McDonough, 2009). These materials flow through three levels of the circular economy (Su et al., 2013): the micro level (corporate level), characterised by particular eco-friendly strategies); the meso level (industrial symbiosis associations); and the macro level (city, province or state level).

The focus of our study is the circular economy at the micro-level, i.e., circular supply chains. In supply chain management theory, we found only one definition of a circular supply chain, seen as: "the set of integrated business processes that improve the availability and effective lifetime of installed bases, as well as the responsible disposition of discarded items" (Krikke et al., 2005, 222). However, the circular 
economy is often operationalised and understood in terms of circular flows, which carry value recovery operations: reuse, remanufacturing and recycling (Genovese et al., 2015; Webster, 2015; Lieder and Rashid, 2016; Nasir et al., 2017; Weetman, 2017) and above definition do not reflect all possible inputs into the circular flows. Thus, there is a need for the development of a circular supply chain concept that considers value recovery in the context of circular flows, as well as those elements that might affect their creation.

As value recovery is a common denominator to both the circular supply chains and the reverse logistics literature, to draw main insights on value recovery we reviewed the established literature on reverse logistics, starting from early contributions by Thierry et al., (1995); Carter and Ellram, (1998); Ferguson and Browne, (2001); Rogers and Tibben-Lembke, (2001); de Brito and Dekker, (2002); Beamon and Fernandes, (2004); Blackburn et al., (2004) and Fleischman et al., (2005) to more recent studies (e.g. Jayaraman and Yadong, 2007; Gobbi, 2011; Rahman, 2012; Govindan and Soleimani, 2017) as well as relevant work on closed-loop supply chains (e.g. Krikke, le Blanc and van de Velde, 2004; Kuman and Malegeant, 2006; Guide and van Wassenhove, 2009; Quariguasi Frota Neto et al., 2010; Kenne, Dejax and Gharbi, 2012; Daaboul et al., 2016; Miemczyk, Howard and Johnsen, 2016; Sgarbossa and Russo, 2017). The reviewed literature reveals 1) repeated calls for empirical research on the topic of reverse logistics so that return flows and the emergence of a competitive advantage are better understood (Jayaraman and Luo, 2007; Stock and Mulki, 2009); 2) the need to provide empirical evidence how reverse logistics flows build more sustainable circular supply chains (Miemczyk, Howard and Johnsen, 2016; Genovese et al., 2017); and 3) the lack of studies that provide insights in circular food supply chains: most of the reviewed studies focus on the electronic (e.g. Jayaraman and Luo, 2007; Kumar and Putnam, 2008; Gobbi, 2011), automotive (Rogers and Tibben-Lembke, 
2001; Ferguson and Browne, 2001) and apparel/clothing industries (e.g. Kumar and Malegeant, 2006; Beh et al., 2016).

The food industry in general faces the triple paradox of food waste, food scarcity and environmental pollution: In an era when $15 \%$ of population in developing countries face food shortage and food security issues (FAO, 2012; Papargyropoulou et al., 2014), one third of food in developed countries is wasted (Gustavsson et al., 2011). Though food is biological material, one tonne of food waste results in 1.9 tonnes of $\mathrm{CO}_{2}$ and food waste generated in manufacturing sector is responsible for approximately $35 \%$ of annual greenhouse gas emissions (EC, 2010a), indicating a significant environmental impact of food production (Mena et al., 2014; Weetman, 2017). Thus, food recovery via the creation of circular flows has a high potential to reduce unnecessary production quantities and food waste, as well as to adequately redistribute available food to the right customers. In research on the food industry, there are numerous studies focused on food waste issues (Alexander and Smaje, 2008; Parfitt, Barthel, and Macnaughton. 2010; Mena, Adenso-Diaz and Yurt, 2011; Garone, Melacini and Perego, 2014; Giuseppe, Mario and Cinzia, 2014; Mirabella, Casteallani and Sala, 2014; Papargyropoulou et al., 2014; Wells, and Caraher. 2014; Gharfalkar et al, 2015; Mourad, 2016; Thyberg, and Tonjes. 2016) but hardly any of these explains the creation of circular flows and the factors that affect the creation of circular flows. We respond to this gap in the literature.

This paper is organised as follows. In Section 2 we define the notion of a circular supply chain and discuss value recovery processes as drivers of circular flows, as well as critical elements that influence the creation of circular flows: product residual value, quantities, value from recovery and market for recovered products. From this, we formulate propositions on circular flows in food supply chains, which result from the 
existing theories of reverse logistics. Section 3 describes the methodology used in our study. Sections 4 and 5 present findings from our cases and discussion. Concluding remarks on the limitation of our study and topics for further research are reported in section 6 .

\section{Circular supply chains: A framework and definitions}

In this section, we describe our framework for circular supply chains. This framework combines the literature on reverse logistics and closed loop supply chains (Thierry et al., 1995; Carter and Ellram, 1998; Tibben-Lembke, 2004; Guide and van Wassenhove, 2009; Rahman and Subramanian, 2012; Govindan and Soleimani, 2017) and recent work on circular supply chains (Su et al., 2013; Dervojeda et al., 2014; Genovese et al., 2015; Webster, 2015; Weetman, 2017).

A circular supply chain is an intrinsic part of a circular economy on the micro, corporate level (Webster, 2015; Nasir et al., 2017). We define a circular supply chain as a connected network of organisations involved in the design and management of valueadding processes and value recovery of a product, component or material. Recovered value can be seen in terms of the economic, social or environmental benefits for these organisations and associated stakeholders (Lieder and Rashid, 2016).

Value-adding processes belong to the forward flow that spans primary supply chain members, and typically starts with the production of raw materials, continues with their movement and transformation into semi-final products, and ends with distribution and sale of finished goods (Christopher, 2011). Primary members are directly involved with the flow of material, while supporting members provide resources, knowledge, utilities or assets to the primary members (Lambert and Cooper, 2000). 
Value recovery processes are associated with reverse flows (Kumar and Malegeant, 2006) as well as with circular flows (Webster, 2015; Genovese et al., 2015; Weetman, 2017). A reverse flow represents "the movement of product or materials in the opposite direction for the purpose of creating or recapturing value, or for proper disposal", (Tibben-Lembke and Rogers, 2002, 271). Returned and used products, packaging, logistics units, damaged, out of date and downgraded products can all enter the reverse flow from any point in the forward flow (Fleishman et al., 2005). Value recovery processes include reuse, re-manufacturing, recycling operations and disposal with energy recovery (de Brito and Dekker, 2002; Kumar and Malegeant, 2006; Weetman, 2017). A reverse flow builds on a preceding "original” chain (Fleischmann et al. 2005) and creates a circular flow, in closed (Kumar and Malegeant, 2006) or openloop supply chains (Blackburn et al., 2004). In a closed-loop supply chain, sources and sinks coincide and, thus, flows cycle in the system (Rahman and Subramanian, 2012). Krikke, le Blanc and van de Velde (2004) state that in closed-loop supply chains products, components or materials return to the primary supply chain members, while in open-loop supply chains they are recovered by alternative supply chains, i.e., they serve different markets (Tibben-Lembke, 2004; Fleischmann et al. 2005). In a circular economy framework, alternative supply chains and markets can be in the same or different industry sectors as the primary supply chains. Weetman (2017) refers to the former as 'open-loop, same sector', and to the latter as 'open-loop, cross-sector'.

Thus, circular supply chains integrate forward and reverse flows in the context of both closed- and open-loop supply chains. The circular supply chain is presented in the Figure 1. 


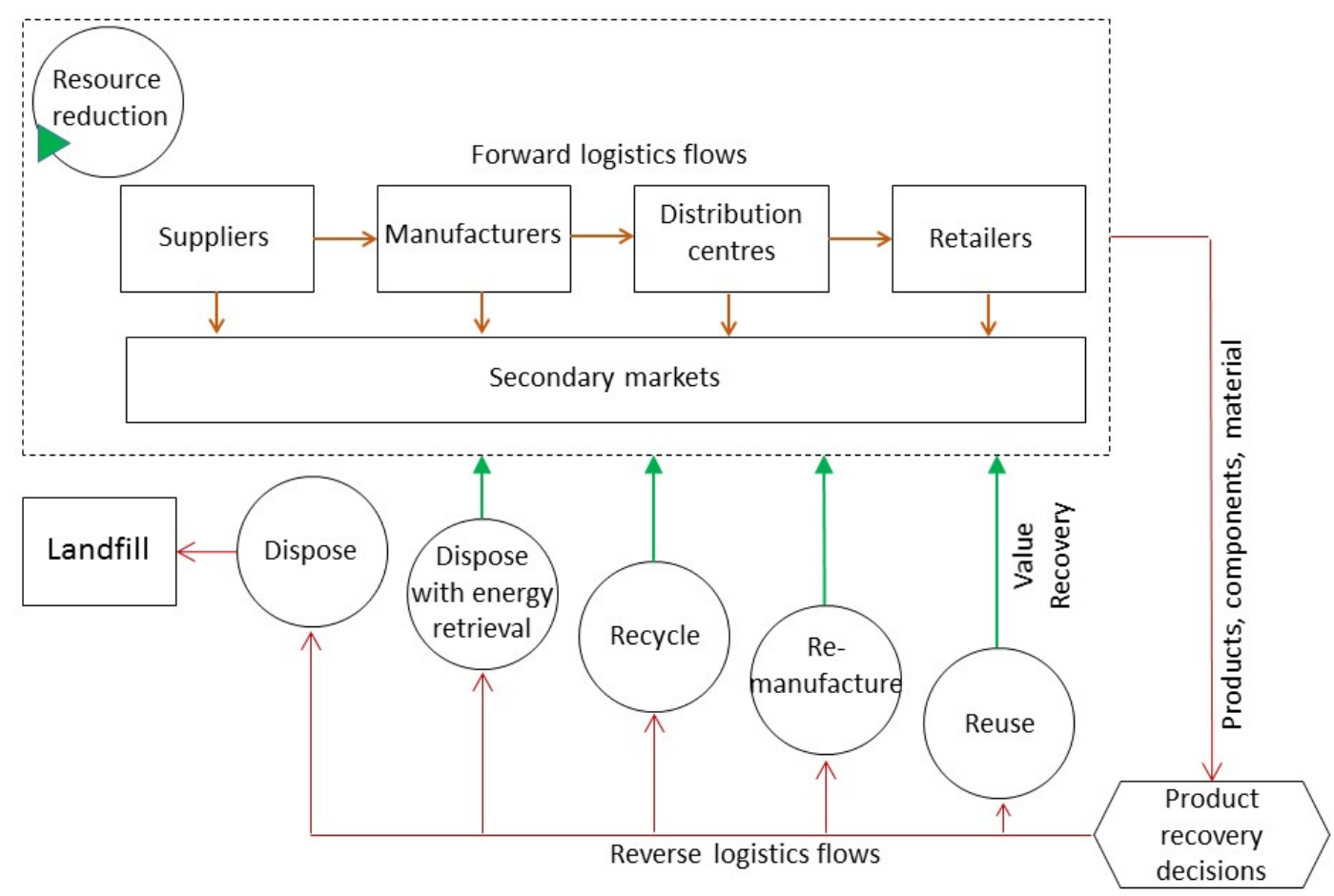

Figure 1. Circular supply chains (adapted from Vlajic, Bogdanova and Mijailovic, 2016)

As value recovery and circular flows are at the heart of the circular supply chain, it is of utmost importance to understand their characteristics, as well as the critical factors that affect them.

\subsection{Value Recovery Processes: A loop view}

To define value recovery processes in context of circular flows, we merge works on reverse logistics hierarchy processes (Carter and Ellram, 1998) and recent works on circular economy (Webster, 2015; Weetman, 2017). Value recovery process is a vehicle in the loop of particular circular flow.

- The first, inner loop of circular flows involves 1) 'maintenance', which aims to "extend and prolong the product life in its first cycle of use" (Weetman, 2017, 38) and 2) 'Resource Reduction', which aims to reduce input of virgin resources by 
getting input from other loops, as well as to increase use of renewable resources. This process is not categorised as a recovery option (see Thierry et al., 1995; Kumar and Malegeant, 2006).

- The second loop of circular flows corresponds to 'Reuse', defined as a "process in which recovered product is used again for a purpose similar to the one for which it was originally designed", Rahman, $(2012,341)$. Reuse represents recovery of $a$ product (Weetman, 2017) which typically results from commercial and lease returns (Fleischmann et al., 2005). Reuse represents a high value recovery process (Gobbi, 2011), as it preserves a maximum of the original value added (Fleischmann et al., 2005, Dervojeda et al., 2014), and can reduce purchasing, transportation and disposal costs (Giuseppe, Mario and Cinzia, 2014). Possible strategies for reuse are reselling, second-hand trading (usually at discounted prices) and donations (Tibben-Lembke, 2002; Weetman, 2017), which implies limited profitability for businesses (Fleischmann et al., 2005). Donations might cause possible ethical concerns in the case of end-of-life products (TibbenLembke, 2002).

- The third loop of circular flows corresponds to 'Remanufacturing'. In the supply chain management literature, remanufacturing is also referred to as reconditioning, repair, upgrade or refurbishment (note: some authors classify repair together with reuse). These terms denote differences in the reprocessing options and the identity and functionality of the end product that results from value-added recovery processes (Thierry et al., 1995). Rahman (2012, 342) defines remanufacturing as a "process of reducing a product into its constituent parts". It represents recovery of components, which may serve as spare parts for a new production output (Fleischmann et al., 2005). Remanufactured products of 
the same quality as a new product (Tibben-Lembke, 2004) are offered to the same market as the original products (Gobbi, 2011). When they are distinct, the main challenge is to manage consumer perceptions related to their value (Atasu, Guide and Wassenhove, 2008). Due to its nature and the inherently higher amount of variability of input quantity and quality, remanufacturing is characterised by costly operations as well as technical and operational bottlenecks (Guide and Van Wassenhove, 2009).

- The fourth, outermost loop of circular flows corresponds to 'Recycling'. Recycling is the process of collecting and disassembling used products, components and materials, separating them into categories and processing them into recycled material (Huge Brodin and Anderson, 2008). Recycled materials do not retain the functionality of used parts of products (Thierry et al., 1995). Thus, recycling represents recovery of material. Recycling is perceived as a low value, time insensitive recovery process (Gobbi, 2011), which mostly reduces disposal costs and tends to be profitable only for a few material fractions, e.g. precious materials or large scale operations (Fleischmann et al., 2005). Moreover, when conducted on an international scale, it incurs substantial transportation cost (Dervojeda et al., 2014).

- Disposal with energy retrieval is based on energy recovery through incineration of products (Carter and Ellram, 1998). 'Disposal in Landfill' is not part of any circular flows as it does not provide any value recovery.

In this study, we focus on reuse, remanufacture and recycling as key recovery processes, and that way indicate possibilities for resource reduction in further research. 


\subsection{Product Recovery: Critical factors}

Product recovery (also called asset recovery) is "the classification and disposition of returned goods, surplus, obsolete, scrap, waste and excess material products, and other assets, in a way that maximises returns to the owner, while minimising costs and liabilities associated with the dispositions" (Rogers and Tibben-Lembke, 1998, 66), and its objective is "to recover as much of the economic (and ecological) value as reasonably possible" (Thierry et al., 1995, 114). As managing return flows is a complex, costly, time and effort consuming process, most organisations focus solely on the cost (Quariguasi Frota Neto et al., (2010) and miss the value (re)captioning aspect (Kumar and Malegeant, 2006), which is a focal point of the circular economy and circular supply chains (Weetman, 2017).

Research on reverse flows as part of closed-loop supply chains is well documented (Fleischmann et al., 2005; Atasu, Guide and Wassenhove, 2008). Guide and Van Wassenhove (2009) identified critical factors that affect profitability from remanufacturing, the most demanding recovery process. In this study, we use these factors in the context of other recovery processes as well, and the creation of loops in circular supply chains.

Value from recovery: Guide and Van Wassenhove $(2009,12)$ state that for business systems, "value recovery must exceed the costs of recovery options", implying need for the cost efficiency and effectiveness of the value recovery process. They state that (financial) value from recovery is a necessary but not sufficient condition, implying the importance of other factors as well. In reverse logistics, value is increasingly seen through the sustainability lens of environmental benefits (Tsoulfas and Pappis, 2006; Linton, Klassen and Jayaraman, 2007). The circular economy perspective considers also 
social ecology (Weetman, 2017), e.g. the creation of new business opportunities and employment, support of non-governmental organisations, etc.

Market for recovered products: The market is "the single most important factor determining the profitability of any reverse logistics program" (Fleischmann et al., 2005, 172). Finding customers for recovered products can be a challenge (Thierry et al., 1995) due to 1) industry, trade or consumers related legislation (Carter and Ellram, 1998; Ferguson and Browne, 2001) and 2) potential attitude of customers towards recovered products as having lower quality, or being "out of fashion (Fleischmann et al., 2005). On the other hand, environmentally educated or conscious customers may give more value to recovered products (Dowlatshahi, 2000). Regardless, customers might be part of the primary or alternative markets in the same or different sectors (Krikke, le Blanc and van de Velde, 2004; Weetman, 2017). Beamon and Fernandes, (2004) and Rahman and Subramanian (2012) suggest that a) reuse and remanufacturing loops typically feed into primary markets; and b) recycling loops typically feed into alternative markets.

Product quality (product residual value): In circular flows, one of the key challenges is the heterogeneous quality of products in reverse flows (Rahman, 2012), which imposes grading, i.e., product disposition and the sorting process for successful recovery (Fleischmann et al., 2005; Stock and Mulki, 2009). The assessed value of the product after grading, but before entering the reverse flow, is called product residual value (Gobbi, 2011; Holweg, Teller and Kotzab, 2016). Its assessment depends on the product characteristics, process and legislative requirements (Thierry et al., 1995). To reduce recovery costs by selecting the right recovery process for the right product, early assessment of product residual value is beneficial (Blackburn et al., 2004). Based on the study of electronic products recovery, Gobbi (2011) found that residual value 
determines recovery process: the higher residual value, the higher recovery process corresponds to it (e.g. high residual value goes to reuse or remanufacturing). However, this study focuses only on closed-loops, and does not consider effects of quantities in the recovery process.

Quantities in product recovery: Cost-effective production and logistics operations in both, forward and reverse flows, are driven by the economy of scale (Chopra and Meindl, 2013). As each type of reverse flow has specific uncertainties (Thierry et al., 1995), economies of scale are not always feasible, which might hinder the creation of 1) closed-loops due to need to collaborate with third parties that have different objectives (Miemczyk, Howard and Johnsen, 2016); 2) open-loops, as third parties, specialised in product recovery require scale for efficient operations (Rogers and Tibben $\square$ Lembke, 2001). While economies of scale can be achieved by pooling or centralising operations, decentralisation provides opportunities for early identification of product recovery value and proper streamlining (Blackburn et al., 2004). Regardless of the product recovery value (Gobbi, 2011) many companies today opt for centralised grading and sorting process (Fleischmann et al., 2005).

We distill the following statements from the surveyed literature (Beamon and Fernandes, 2004; Krikke, le Blanc and van de Velde, 2004; Rahman and Subramanian, 2012; Guide and Van Wassenhove, 2009; Gobbi 2011):

- Statement S1: Financial value from recovery is a necessary condition for the profitability of operations of any value recovery process in supply chains, but not for the occurrence of the corresponding loops themselves in the circular flow.

- Statement S2: Reuse and remanufacturing loops typically feed into primary markets, while recycling loops typically feed into alternative markets. 
- Statement S3: The higher the residual value of the product, the more likely the higher value recovery process will be chosen.

\subsection{Specificities of food supply chains}

Research on reverse logistics and product recovery in food supply chains is exceptionally scarce, and in terms of circular food supply chains is in its infancy. Main contributions focus on developing the concept of marginal value of time and corresponding mathematical models (Blackburn et al. 2004 and Blackburn and Scudder, 2009), optimisation of return flows between a supplier and a retailer (Hahn, Hwang and Shinn, 2004), developing a new model of sustainable, closed-loop meat supply chains and the creation of new, open-loops in cross-sectors (Sgarbossa and Russo, 2017). Only the two studies by Holweg, Teller and Kotzab, (2016) and Stock and Mulki (2009) focus on an empirical investigation of possible circular flows in food networks. The former offers insights into product recovery in fresh food supply chains, but considers only issues on the retail and wholesale level. There are no insights into the upstream part of the chain, as well as what influences the creation of loops in the food supply chain. The latter study focuses on product returns, but does not provide a discussion on return flow issues in food supply chains, which contributed more than $50 \%$ in the sample of the survey.

Other food related studies mostly focus on waste management and issues of waste causes (e.g. Mena, Adenso-Diaz and Yurt, 2011; Mena et al., 2014), its measurement and classification (e.g. Parfitt, Barthel, and Macnaughton, 2010; Papargyropoulou et al., 2014; Gharfalkar et al., 2015), and new, clean technologies (Despeisse et al., 2012) and other possibilities of food waste reduction (e.g. Mirabella, 
Castellani and Sala, 2014; Garrone, Melacini, and Perego, 2014; Mourad, 2016; Thyberg and Tonjes, 2016).

There is a clear gap in the literature regarding the understanding of circular flows in food supply chains, in particular concerning: 1) how critical factors (value from recovery, residual value, available quantities, and the market for recovered products) influence creation of circular flows in food supply chains; 2) how residual product value affects recovery processes; and 3) what form loops in the circular flows take.

Based on the theory and statements presented in section 2.2., we formulate the following propositions:

P1 (based on Statement S1): Financial value from recovery is a necessary condition for profitability of operations of any value recovery process in fresh food supply chains, but not for the occurrence of the corresponding loop itself in the circular flow.

Proposition P1 is tested separately for each value recovery process: reuse, remanufacturing and recycling.

P2 (based on Statement S2): Reuse and remanufacturing loops typically feed into primary markets in fresh food supply chains. Recycling loops typically feed into alternative markets in fresh food supply chains.

P3 (based on the Statement S3): The higher the residual value of the product, the more likely the higher value recovery process in fresh food supply chain will be chosen.

\section{Methodology}

Our research investigates the current state of practice and value recovery as a part of circular food supply chains. This requires close observation of real business operations and the mapping of value recovery processes as a contextual exploration of events in 
supply chains in real time. Therefore, this study lends itself to a case study approach (Yin, 2014). Moreover, case studies are suitable for investigating several stages of a supply chain (Seuring, 2008), and are therefore suitable for analysis of circular flows.

The unit of analysis in the study is the value recovery process. In common with Oglethorpe and Heron (2013), we use multiple case studies. To ensure case study rigor, case selection, data collection, validity and reliability have to be carefully considered in the methodological design (Seuring, 2008).

\subsection{Case selection}

Value recovery processes differ by type and size of companies (Stock and Mulki, 2009), as well as by the organisation of the product recovery process (location of recovery, type, input and output) (Autry, Daugherty and Richey, 2001) and type of the reverse flows (e.g. centralised or decentralised) (Blackburn et al., 2004). Cases are therefore selected to explore a variance of processes across the sector considering the size of the companies and extent of the geographic region, as circular flows are likely to occur in companies that are located in proximity to each other (Chertow, 2007).

We identify circular flows in three networks in the agri-food industry from which we draw our cases. Networks A and B exhibit decentralised value recovery processes, implemented individually by small and medium enterprises (SMEs). Network $\mathrm{C}$ has centralised value recovery processes upstream and downstream of the supply chain, driven by the large companies. All networks operate within an area of $45 \mathrm{~km}$ radius.

We consider 24 cases made up of seven cases in network A; eight in network B; and thirteen in network C. A 'case' centres on one organisational unit, which has its own value recovery practices (e.g. retail outlets, wholesalers, and processing facilities). 
Each case is labelled according to the company it belongs to and the type of organisational unit (e.g. A1P - Company A1, Producer), presented in Table 1.

Table 1. Overview of cases in the study

\begin{tabular}{|c|c|c|}
\hline $\begin{array}{l}\text { Company } \\
\text { code }\end{array}$ & $\begin{array}{l}\text { Size of the } \\
\text { company }\end{array}$ & Org. unit (Case code) \\
\hline A1 & Medium & Grower (A1P); Washer \& Packer (A1PR) \\
\hline $\mathrm{A} 2$ & Medium & Grower (A2P); \\
\hline A3 & Medium & Wholesaler (A3W) \\
\hline A4 & Small & Retail (A4R) \\
\hline A5 & Medium & Bakery (A5PR) \\
\hline A & Large & Farmer $(\mathrm{P})$ \\
\hline A, B & Large & Public facility for waste processing (AWM), (BWM) \\
\hline B1 & Large & Grower (B1P); Packer (B1PR) \\
\hline B2 & Large & Grower (B2P); \\
\hline B3 & Medium & Wholesaler (B3W) \\
\hline B4 & Small & Retail (B4R) \\
\hline B5 & Small & Bakery (B2PR) \\
\hline B & Large & Farmer (BP) \\
\hline B & N.a. & Food bank (BFB) \\
\hline $\mathrm{C} 1$ & Large & Grower (C1P); Packer (C1PR) \\
\hline $\mathrm{C} 2$ & Medium & Grower (C2P); Washer \& packer (C2PR) \\
\hline $\mathrm{C} 3$ & Medium & $\begin{array}{l}\text { Grower (C3P); Washer \& packer (C3PR); Waste processor } \\
(\mathrm{C} 3 \mathrm{WM})\end{array}$ \\
\hline $\mathrm{C} 4$ & Large & $\begin{array}{l}\text { Retail }(\mathrm{C} 4 \mathrm{R}) \text {; Distribution centre }(\mathrm{C} 4 \mathrm{~W}) \text {; Retailer's facility for } \\
\text { waste processing }(\mathrm{C} 4 \mathrm{WM})\end{array}$ \\
\hline
\end{tabular}




\begin{tabular}{|l|l|l|}
\hline C & Small & Private facility for waste processing (CWM) \\
C & N.a. & Food bank distributor and soup kitchen (CFB) \\
\hline Total & Network A: 7 cases \\
& Network B: 8 cases \\
& Network C: 13 cases
\end{tabular}

Legend: Producers (P); Processors (PR); Wholesalers (W)/ Distribution centres;

Retailers (R); Food banks (FB); Recycling \& energy retrieval facilities (WM)

Initial food retail companies were identified and selected through regional food groups and associations. Contact with retailers was the starting point, as they identified other actors as data collection sites. As theory building relies on theoretical sampling (Eisenhardt, 1989), in the first instance, we mapped the network of the small retailer. To confirm conclusions gained from the first network, we selected the same type of retailer within a similar network of similar types of companies. As networks of SMEs are typically characterised by limited value recovery practices, we also selected a network of a large retailer as a polar case.

The 'type of a business' is identified in line with typical actors in food supply chains: producers, processors, wholesalers, and retailers. Due to the important function of food banks, recycling and energy retrieval companies in a circular supply chain, we included them in the analysis as well. Types of businesses are classified in relation to the number of employees and annual turnover (EC, 2005). We classify food producers, or 'agricultural businesses', in relation to the UK government criteria for size and type (ECARD, 2011; www.nationalarchives.gov.uk). 


\subsection{Data Collection}

We adhere to the criteria commonly used to assess the rigor of field research validity and reliability (Gibbert et al., 2008; Yin, 1994, 2014). We also took note of Guba and Lincoln's alternative criteria for judging the soundness of qualitative research, particularly transferability and confirmability of evidence (Lincoln, 1995).

Data collection consisted of one main interview and an additional interview or follow-up correspondence with company representatives to obtain additional information. Evidence was generated through a case study protocol (Yin, 2014), and a combination of data sources in order to triangulate and so address issues of internal and external validity, as done in the study of Oglethorpe and Heron, (2013). We used at least three data sources for each case for the purposes of triangulation and confirmability. The case protocol consisted of four parts: General information (about companies and interviewees); Product characteristics (input and output format, quality, quantity, supplier and customer); Process characteristics (e.g. re-grading and determining product residual value, choice of recovery process, its form and characteristics), and Value (motives for and value from recovery: financial, social, environmental; an indication of profitability from the recovery operations).

The cases comprise of 34 interviews and 26 observations. In some cases, instead of observation, available company documentation was used (three companies). Key information was obtained from case participants (owners or company managers) via semi-structured interviews. The criteria for selecting respondents included at least five years of employment in the food industry and current employment in a managerial position at the enterprise. For SMEs, we interviewed shop owners who usually assume multiple roles in the company's operations. The interview duration was one hour on average and most interviews were audio recorded and transcribed. Alternatively, detailed notes were taken and transcribed later. 
We were granted access to company suppliers and/or buyers, which enabled us to cross-check the evidence gained through interviews. We interviewed at least one supplier and one customer of each company. We did not interview end customers (households), energy companies and seed suppliers. At least one observation of unit operations and facilities was carried out for every type of participant (e.g. interview in situ at farm visit, etc.). An exception was made for recycling and energy retrieval facilities where interviews and meetings took place in the main offices of the company.

\subsection{Data Analysis}

We documented all interviews, observations and access to public documents by creating a data-base (in NVivo software). As case protocols were based on semistructured interviews, we could systematically and consistently examine each case.

Process maps were generated, illustrating the flow of materials and the relationships between case units for each network, focusing on different classes of products in circular flows (e.g. surplus, returns, unsold), their residual values, their origin (entry to the circular flow), destination (customers of recovered products), and the type of value adding recovery they are subject to (measures are presented in Table 2).

Table 2: Measurement

Element

Residual value (Gobbi, 2011; Holweg, Teller and Kotzab, 2016)

- Low: 2L class and below

- High: 2M class and above

Quantity (Holweg, Teller and Kotzab, 2016), and input from interviewees 
- Low: a few crates or 1 to 2 pallets per week on average

- High: at least full load lorry per day on average

Market (Beamon and Fernandes, 2004; Krikke, le Blanc and van de Velde, 2004;

Rahman and Subramanian, 2012)

- primary customers (regular, key customers)

- alternative customers (occasional or new customers), in same or different sector

Value

Financial: (Guide and Van Wassenhove, 2009)

- Yes: Cost of recovery operation < value recovered (small difference or large difference)

- No: Cost of recovery operation $>=$ value recovered (small difference or large difference)

* we consider value recovery in financial terms, as revenue from recovered products Social: (Garetti and Taisch, 2012; Giuseppe, Mario and Cinzia, 2014)

- Yes: donations, coverage of distribution costs, etc.

Environmental: (Tsoulfas and Pappis, 2006; Linton, Klassen and Jayaraman, 2007)

- Yes: soil improvement, food waste reduction

Guide and Van Wassenhove $(2009,11)$ state that "for each type of product return, there is a most attractive recovery option". Our unit of analysis is the value recovery process in the circular flows of food supply chain networks. To distinguish loops in the supply chain we use the transformation process model to describe the nature of operations consisting of input, transformation and output (Slack, BrandonJones and Johnston, 2013). As inputs, we consider products, components and materials that are recovered to output (reused, repaired or a new product, Weetman, 2017) through transforming resources such as facilities, equipment and staff. 
Based on coding procedures suggested by Miles, Huberman and Saldana (2014, 73), qualitative information from interviews and observations is coded (first cycle coding) to identify value recovery flows and create a diagrammatic representation of the value recovery in all three networks, as well as a narrative description. Subsequently, we applied a second cycle of coding within each value recovery process to analyse influence of critical factors to these value recovery activities.

\section{Findings}

Our findings present an analysis of the flow of material of different classes of products, their residual values, origin, destination and type of value recovery they are exposed to, approximate quantities, value from recovery, and indicated profitability for each company the three networks.

In these networks producers grow a mix of brassica vegetables (e.g. broccoli, cauliflower, cabbage) and root vegetables (e.g. carrot, potato, parsnip). Brassicas are considered clean products, they are packed for dispatch immediately after harvesting and grading, whereas root vegetables require washing and grading, before packing. Both groups of vegetables must be stored and transported under temperature controlled conditions.

If kept in non-optimal environments - even during one stage of the supply chain - the perishability of these products increases, and consequently their value decreases. However, due to biological processes, any damage may only become apparent at the retail stage or beyond.

Brassicas and root vegetables are not subject to specific marketing standards (DEFRA, 2011), so their classification is defined by the supplier and/or customer. Typically, fresh vegetables are classified by size, colour, and appearance as "Class 1" 
and "Class 2". Class 1 products have a desirable size, colour and appearance, while Class 2 products vary from these norms in one or more criteria. For example, too big or too small products of correct colour and appearance or incorrectly sized products with small blemishes are classified as high quality class 2 (Class $2 \mathrm{H})$, while low quality rated products were considered as unsaleable by all participants in the study.

Surplus and return of products of all product classes might happen at any stage of the supply chain, and it consists of all kinds of products. Specificity of vegetables is that their appearance worsens over time, and there is a weight loss, which requires regrading and repeated evaluation of residual value.

\subsection{Networks $A$ and B}

Networks A and B are presented in Figures 2 and 3, and explained together as they have similar structure and characteristics.

Crop producers (growers: A1, B1) are at the beginning of the forward flow, and they also perform processing activities: Packing only (B2) or washing and packing (A2). Grading of vegetables takes place during the harvest (especially when done manually, e.g. broccoli), or during washing and packing (e.g. potato).

Class 1 vegetables are sold to the wholesaler (A3, B3), being the key customer. However, in favorable weather conditions growers have crop surpluses, much of it of high quality, which cannot be sold to the key customer. Large grower B1 profits from larger quantities which are sold to alternative customers (e.g. small wholesalers or wholesaler markets). Mid-size grower A1 makes a decision dependent on the type of product and probability of profitable sale: When a surplus is expected, very perishable products are not harvested, and if they are, they usually finish as animal feed at the nearby farm. "There are several farms around with cauliflower, if I have surplus, they have it as well, and it is very difficult to find a new buyer in a couple of days. Even if I 
find buyer, I have to sell it for a very cheap price, and that does not cover my costs", (Owner, A1). The same rule applies for Class 2 products, products returned from the wholesaler and unsaleable products.

The wholesalers (A3, B3) buy fresh products from local growers and import them from international suppliers as well. Products that do not fit wholesalers' specifications (so called 'out of spec') are typically administratively returned, i.e., wholesalers claim credit due to non-compliance. Only on occasions are products physically returned to the suppliers, especially to international suppliers due to high transport costs. "(Last month) it was first time ever we had to return the full container (of potatoes) back to Spain; it was bad and we couldn't do anything with it.", (Managing Director, A4). Class 1 products are sold to key customers (Retailers A4 and B4, as well as Food services A5, B5 respectively), while surpluses and returns are regraded, re-labelled (if product is downgraded), repacked (if necessary, at wholesaler A3), discounted and resold: while wholesaler A3 prefers selling of these products to small wholesalers, or other alternative customers, wholesaler B3 prefers to sell these products to the key customers. Returns from the key customers are mostly deemed unsaleable and merged with other unsaleable products. These products are given or sold cheaply to local farmers, or prepared (unpacked, 'decanted') for recycling. (“... all product that do not look fresh immediately go to the bin for pig famer", (Sales representative, B4). As unpacking is very costly and labour intensive, donation of products to the farmers is the preferred option of wholesalers. Farmers unpack them and use them for compost, while better preserved products are converted to animal feed on the farm. 


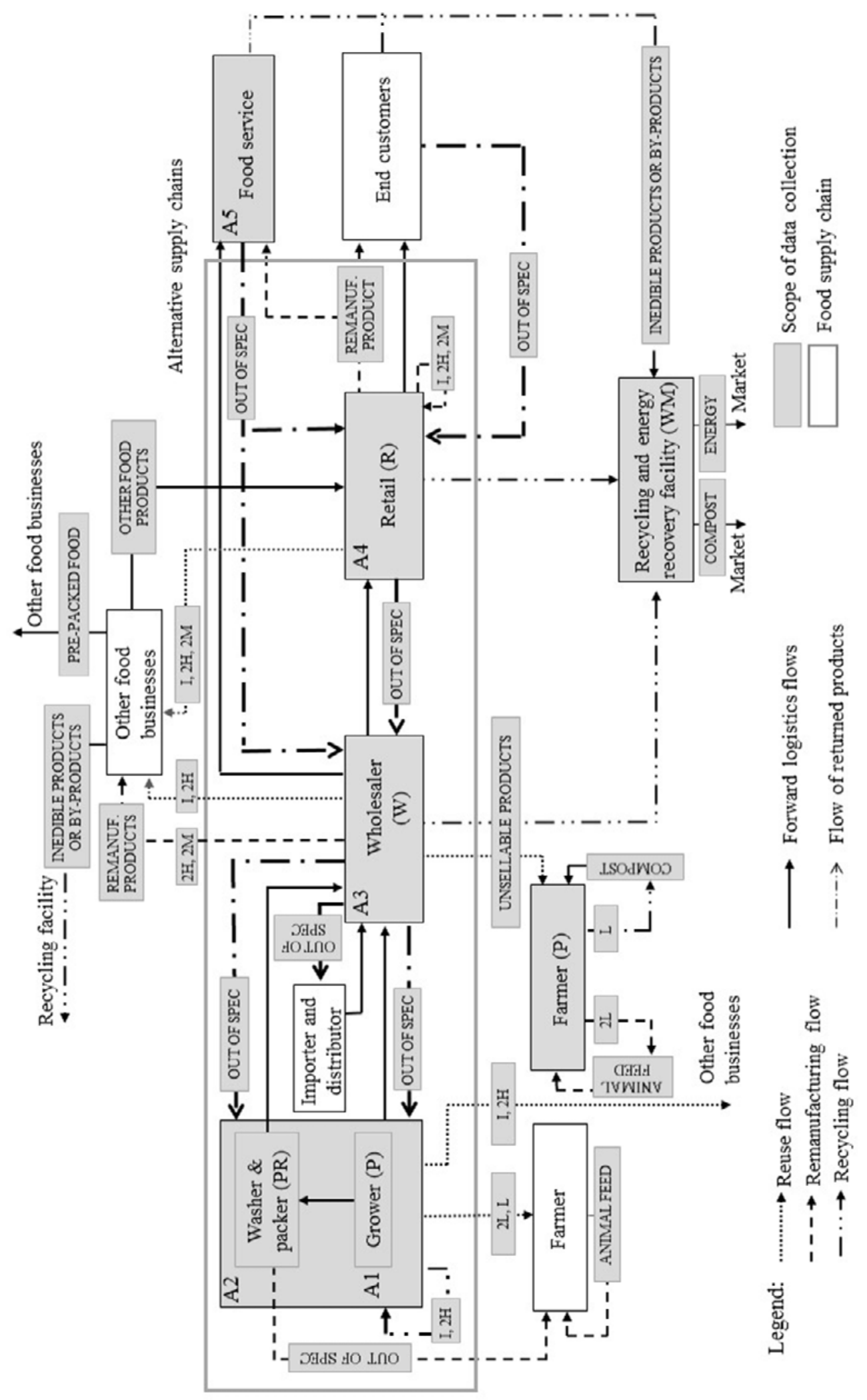

Figure 2. Supply Chain Network A 


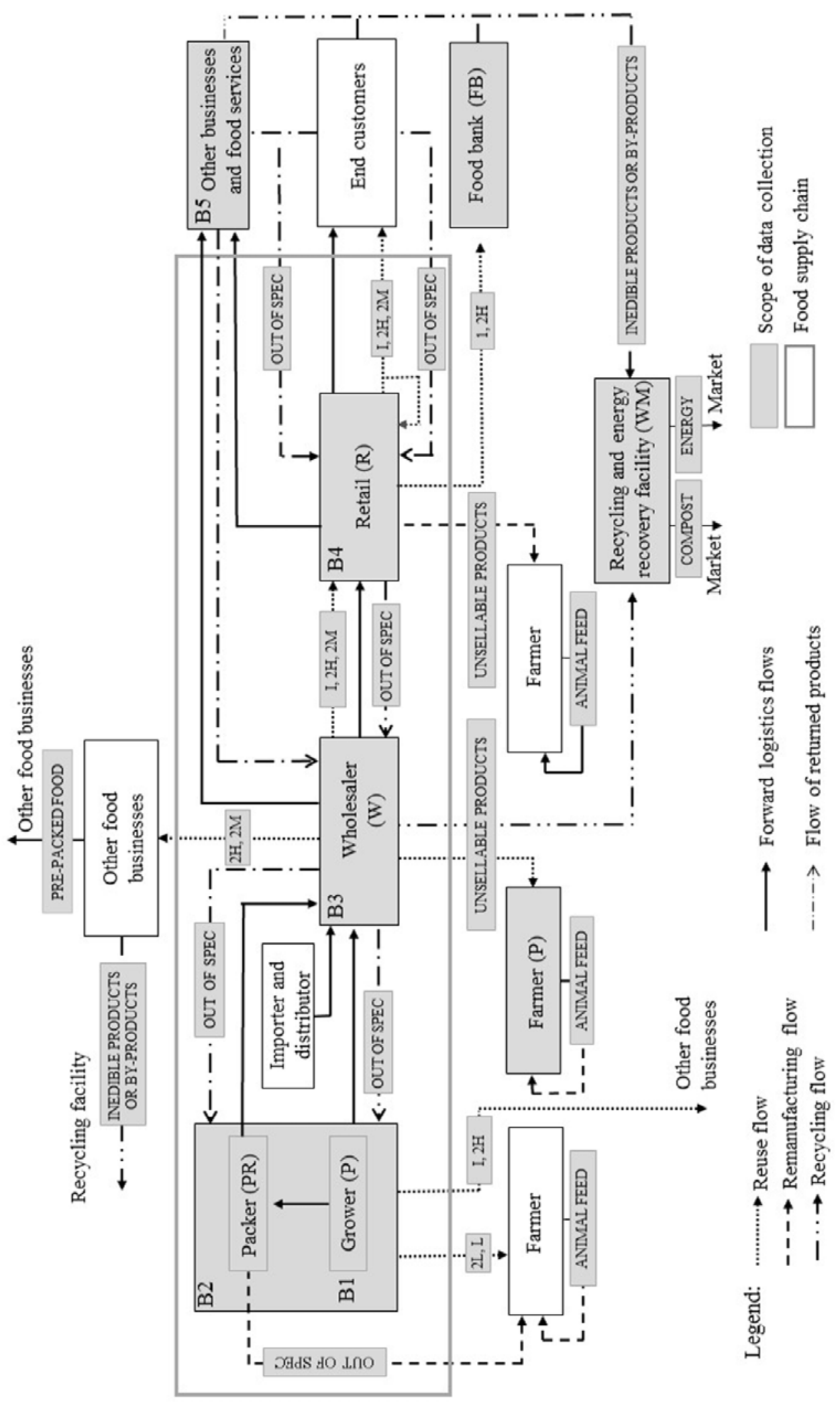

Figure 3. Supply Chain Network B 
Independent small retailers (A4, B4) source fresh food from the wholesalers (A3, B3, respectively) and sell it to food services, business customers and end customers. Inventory rotation of fresh food products at small retailers is very high: they get deliveries of fresh products every morning. Surplus quantities are very small, and when they occur, shop owners offer them to food processors (A5, B5, respectively) or use them internally. If products are damaged or of lower quality than expected, retailers return them to wholesalers. Return handling depends on the relationship between the wholesaler and the retailer, and the former's return policies. "We track all of our products, and when our customer returns the product, we register that as well. So, we know is the customer "serial returner", what is returned and why. Sometimes they (customers) have good reasons to return the product, but sometimes they don't.", (Sales representative, B3). Retailer A4 has developed an internal monitoring and grading system, to separate products that are not sold within time, as well as products that show early signs of damage. "Potatoes, parsnips, and similar products, there is not much waste here, they can be processed and used..." (Owner, A4). For example, vegetables are made into soup ingredients in the shop and sold on the premises or to the food service for higher prices than raw fresh products. Retailer (B4) donates small quantities of food to the local food bank once or twice per year. This flow is not typical highly perishable products as they fast became unsaleable. Retailers A4 and B4 have different practices for handling unsellable food. Retailer A4 prepares unsaleable products for recycling by separating products from packages. These products are transported weekly to the local recycling and energy recovery facility, an in-tunnel vessel producing compost and energy from food. "All separated organic waste goes to recycling, and requirements for commercial businesses are getting stricter: all businesses that generate more than $50 \mathrm{~kg}$ per week of organic waste need food waste collection... next 
year (2017) it will be 5kg" (Waste management officer). B4 separates unsaleable products in a small bin, which is given to the local farmer who collects it two or three times a week. Retailer B4 is located on a busy city street where there is no food waste collection service.

\subsection{Network C}

The beginning of the forward flow in this network (Figure 4) differs from networks A and B only in the size of the companies and key customers. Producer (C1) is classified as large, and processors (C2 and C3) are mid-size companies that have separate organisational units for production, food processing and recycling of organic waste. They all sell products to the same key customer, the large retailer (C4). There are three flows of Class 1 products between suppliers and retailer's regional distribution centre (RDC): 1) loose products delivered directly from companies (C1, C2 and $\mathrm{C} 3$ ); 2) pre-packed products delivered from washing and packing units (C2PR, C3PR); and 3) processed pre-packed products, delivered from processing unit (C3PR). The large retailer also imports products from international suppliers.

There is occasionally a surplus of class $2 \mathrm{H}$ products at growers, as class 1 products are absorbed by the retailer. Class $2 \mathrm{H}$ usually remain on site after grading, washing and/or packing or they are rejected by the retailer and returned to the supplier. Grower $\mathrm{C} 1$ and Processor C2 prefer to sell surplus to other wholesalers or on the wholesale market. Their revenues from sale to food processor often do not cover the cost of harvesting and packing. Lower quality products are often deemed as unsaleable on wholesale markets, so products are sold to a nearby farmer, who uses them as animal feed. "We regularly work with a farmer nearby, we sell him vegetables for a small fee" (Manager, C2). Products graded as unsaleable during the harvest are left on the field. 
The processing facility of the company $\mathrm{C} 3$ consists of two departments: One for grading, washing and packing (pre-packed whole products) and another for food processing and packing (pre-packed processed products). Grading and washing of root vegetables is done mechanically, using two-dimensional imaging. During this process, a small percentage of products are rejected and together with soil from the machine are returned to the fields and used as compost. Class 1 products are separated, inspected and packed in required packing format, and transported to a RDC. All other products are sorted and returned for further processing (cutting, peeling, shredding, etc.). Class $2 \mathrm{H}$ products are treated as manufacturing returns, separated and packed for other retailers, food services and ready meal manufacturers. Lower graded products, as well as byproducts and returned products are sent to an anaerobic digester (C3WM), which produces enough energy to meet the needs of the company, with the surplus sold to the local energy company. "We do not have surplus that we cannot handle. If harvest is better than expected, we have special storage to keep the products fresh. We sell them to different customers", (General Manager, C3).

Large retailer $(\mathrm{C} 4)$ has 26 retail distribution centres and more than 500 stores in UK, of which one RDC and 18 retail outlets in the study area. 17 outlets have recycling resources, and six outlets have a café. Next to each RDC is a facility where material for recycling is collected from the regional network, and then baled. From each store, material for recycling is collected after delivery of fresh products. The retailer's purchasing strategy is to source locally, and import products when they are not available locally. The retailer has a set of specifications for each type of product they sell: loose products and pre-packed and economy packs. If one of the specifications is not fulfilled, the retailer labels products as 'out of specification' and claims a return. Each return is noted in the supplier's 'score-card'. In most cases, the return of products is 
administrative, as the cost of collection from outlets would penalise suppliers. "Last year we made mistake during packing, so product was mislabeled as local. I reported the mistake on forty crates of products, and I had to pay $£ 17,500$ for forty crates" (Manager, C2). From the RDC, damaged or lower quality products are transported to a pet-food producer, and all other products are transported to the retailers recycling and energy recovery facility in UK, where an anaerobic digester produces compost and energy. Surplus occurs regularly at the retailer's outlets, and since April 2016 fresh food has been donated to a food bank distributor on a daily basis. This distributor supplies regional food banks and charities. Fresh food is mostly used in soup kitchens, to be given away, or sold for a nominal sum. 


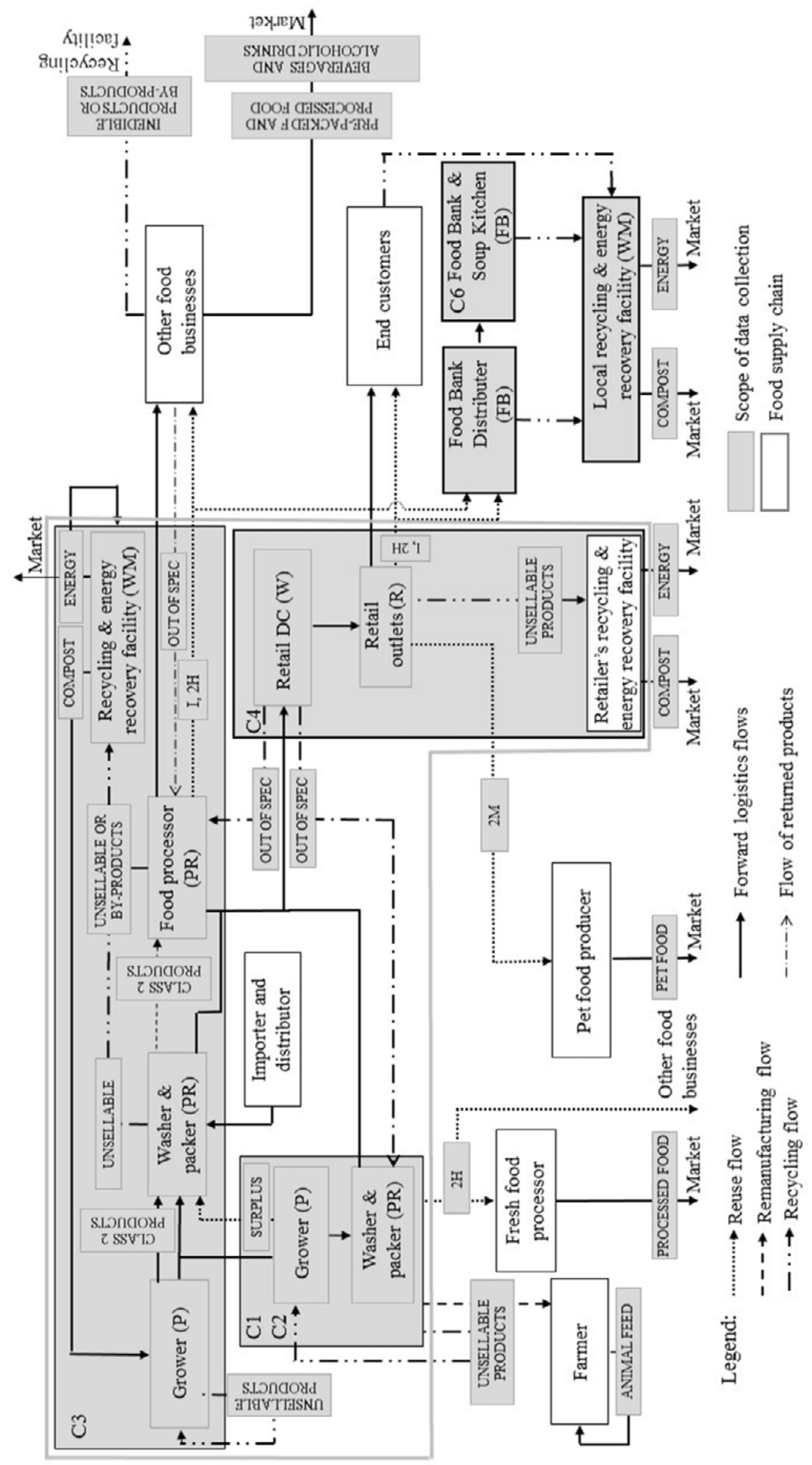

Figure 4. Supply Chain Network C 


\section{Discussion}

In this section, we present a cross-case analysis for each value recovery process and test Propositions 1 and 2 presented in Section 2.3.

\section{1. 'Reuse' value recovery process}

Proposition 1a: Financial value from recovery is a necessary condition for profitability of a company engaged in reuse, but not for the occurrence of the 'reuse' loop itself.

Table 3 shows that financial value is a necessary condition for profitability of a company from value recovery operation, specifically from resale by discounting (Mulhern and Padgett, 1995; Stock and Mulki, 2009). In instances of negative economic value, profitability is not achieved. As resale by discounting is common for high residual value and high quantities of products (Holweg, Teller and Kotzab, 2016), specific to fresh food supply chains, low residual value products are also part of the profitable reuse process. For example, a retailer in network $\mathrm{C}$ resells large quantities of low residual value food products to a manufacturer of pet food. Though discounting, the large retailer still has a margin on the sale of these products (Wilson, 1996, Hingley, 2005; Hamister and Suresh, 2008). As observed in networks B and C, producers or processors resell food products to farmers for a price often lower than production costs, which can jeopardise profitability of value recovery (Mirabella, Castellani and Sala, 2014), and potentially create a barrier to a circular flow. 
Table 3. Reuse flows

\begin{tabular}{|c|c|c|c|c|c|c|}
\hline Network & $\begin{array}{l}\text { Product } \\
\text { residual } \\
\text { value }\end{array}$ & Quantity & Market & Value & Profitability & $\begin{array}{l}\text { Circular } \\
\text { flow }\end{array}$ \\
\hline A & High & High & Open & $\mathrm{F}(++)$ & Yes & Yes \\
\hline \multirow[t]{2}{*}{ B } & \multirow[t]{2}{*}{ High } & \multirow[t]{2}{*}{ High } & Open & $\mathrm{F}(++)$ & Yes & Yes \\
\hline & & & Closed & $\mathrm{F}(++)$ & Yes & Yes \\
\hline \multirow[t]{2}{*}{$\mathrm{C}$} & \multirow[t]{2}{*}{ High } & \multirow[t]{2}{*}{ High } & Open & $\mathrm{F}(-), \mathrm{S}, \mathrm{N}$ & No & Yes \\
\hline & & & Closed & $\mathrm{F}(+)$ & Yes & Yes \\
\hline A & High & Low & Open & $\mathrm{F}(+)$ & Yes & Yes \\
\hline \multirow[t]{2}{*}{ B } & \multirow[t]{2}{*}{ High } & \multirow[t]{2}{*}{ Low } & Open & $F(-), S$ & No & Yes \\
\hline & & & Closed & $\mathrm{F}(+-)$ & Conditional & Yes \\
\hline \multirow[t]{2}{*}{$\mathrm{C}$} & \multirow[t]{2}{*}{ High } & \multirow[t]{2}{*}{ Low } & Open & $\mathrm{F}(+)$ & Yes & Yes \\
\hline & & & Open & $F(-), S$ & No & Yes \\
\hline A & Low & High & No & No & No & No \\
\hline B & Low & High & No & No & No & No \\
\hline $\mathrm{C}$ & Low & High & Open & $\mathrm{F}(++)$ & Yes & Yes \\
\hline A & Low & Low & Open & $F(-), S$ & No & Yes \\
\hline B & Low & Low & Open & F (-) & No & Yes \\
\hline $\mathrm{C}$ & Low & Low & Open & F (-) & No & Yes \\
\hline
\end{tabular}

Legend: F - Financial value; $(++)$ significant; $(+)$ small; (-) financial loss; S - Social value; N - Environmental value; Grey fields: Significant reuse flows 
However, Table 3 (column 'Circular flow') shows that 'reuse' loops exist even in instances of non-profitability for the company, as in charitable food donations. The motivation for creation of such loops is primarily focused on providing social benefits via the redistribution of food surplus (Weetman, 2017), as well as the environmental benefits via the reduction of food waste (Thyberg and Tonjes, 2016). Though charitable food donations are common practice in retail (Garrone, Melacini and Perego, 2014), there are instances of producers and processors being involved in food re-distribution: "We want to help people, ..., we send three to four crates of products per week to food bank distributor" (General Manager of processing company, network C). Donations of fresh food are often limited (Holweg, Teller and Kotzab, 2016) due to regulatory restrictions for unpacked products, limited cold chain capacity in food banks (Alexander and Smaje, 2008), as well as issues of management and channeling of fresh food to charities (Mourad, 2016). As an employee of a food bank states: "We do not distribute fresh products unfortunately, we do not have a fridge to keep them, but if someone brings us food it is difficult to say - we do not take that" (Employee in food bank, network C). Thus, insufficiently supported large food donations can be assessed as a transfer of food waste risks (Vlajic, Bogdanova and Mijailovic, 2016), or an attempt to reduce disposal costs of food companies (Giuseppe, Mario and Cinzia, 2014), which indicates a potential barrier to a circular flow.

Interestingly, smaller quantities of low residual value products are also a part of donations. A wholesaler in network A donates products to farmers: "It's preferred choice because it saves us time and money - we do not have to decant it.... and we support that way the farm, which works as a social enterprise" (Managing Director). This is an acceptable alternative strategy (Garrone, Melacini and Perego, 2014) and farmers benefit from adding an energy source to their animals' diets (Mirabella, 
Castellani and Sala, 2014). On the other hand, the circular flow might fail if farmers do not take all products (Mirabella, Castellani and Sala, 2014), or do not collect products themselves, as observed at the small retailer in network B. Thus, lack of matching the product and the recipient requests at the end of the circular flow, as well as distribution issues might create barriers to the circular flow.

Proposition 2a: Reuse loop typically feeds into primary markets in fresh food supply chains.

Considering the market for 'reused' food products, Table 3 shows that reuse more often flows to alternative markets, and forms an open-loop. This contradicts Beamon and Fernandes (2004) and Rahman and Subramanian (2012), as they only consider situations of product returns. As Krikke, le Blanc and van de Velde (2004) suggest, possibilities of open-loops are present as well, and they are observable in fresh food supply chains. The key reason is the specificity of food products: "Food is biological material subject to degradation" (Parfitt et al., 2010, 3065) and therefore, subject to change in residual value over short period of time (Blackburn et al., 2004). For example, products returned to the wholesaler due to mistakes in order-picking will likely be downgraded to a lower classification before resale due to the shorter time period until its sell-by-date and to eventual damages or changes in their organoleptic characteristics (colour, surface, texture). As the Managing Director of wholesale (network A) states: "We would try some of them to offload to customers who don't normally buy from us but we do it at a discounted rate." This is a strategy based on product and customer differentiation (Henson and Reardon, 2005), with the aim of creating a profit and ultimately competitive advantage for the company. As alternative customers are other food wholesalers, food processors or producers, services, and food banks, this creates an open loop in the same sector (Weetman, 2017). 
In parallel with open loops, re-selling on primary markets, i.e., closed loops, are found in the downstream parts of networks B and C. This is in line with common sale and inventory management strategies of large retailers, e.g. dynamic pricing (Wang and Li, 2012; Liu, Zhang and Tang, 2015).

A potential barrier in the creation of loops in circular flows are smaller companies, which cannot easily find alternative customers (Jones, Comfort and Hillier, 2004), and do not have strong negotiating power to push surplus quantities to key customers in primary supply chains (Bourlakis et al., 2014) to obtain profitable conditions.

\section{2. 'Remanufacture' value recovery process}

Remanufacturing is rarely considered within food reverse logistics, food waste management and the circular economy literature, as distinctive value recovery process. However, the same literature refers to re-packing or (re)processing of food products as part of reuse or recycling (Stenmarck et al., 2011; Garone, Melacini and Perego, 2014; Holweg, Teller and Kotzab, 2016; Mourad, 2016): re-packing or re-processing of food products for use in human consumption is considered as reuse, while re-processing of food products for use in other purposes, e.g. feed for animals, composting or to create energy is considered as recycling. In our view, it is more appropriate to classify repacking and re-processing as remanufacturing activities because 1) both, re-packing and re-processing of food products requires previous collection, re-grading and sorting (c.f. Ferguson and Ketzenberg, 2006), which is more time, cost and resource demanding than operations related to reuse, e.g. direct reselling or re-distribution issues (Cherrett et al., 2015; Holweg, Teller and Kotzab, 2016); 2) resources required for re-packing (e.g. packing machines/lines, or work-stations) (Stenmarck et al., 2011) and re-processing 
(e.g. shredding and cutting machines) of food products (Garrone, Melacini and Perego, 2014) are very different from resources needed for recycling (e.g. in-vessel tunnelling or anaerobic digestion facilities, Papargyropoulou et al., 2014); 3) re-packing considers removing the spoiled product from the package and/or adding new, fresh items (Stenmarck et al., 2011) which is actually disassembly and reassembly of fresh food packed products.

Our findings show that re-processing typically involves products 1) rejected from the production of the Class 1 products, which are then side-lined to the processing line; or 2) identified as risky for sale to key customers in future period, which are then upcycled (if possible); or 3) returned products. Re-packing typically occurs in situations when a buyer (e.g. wholesaler) received products out of specification, but in sufficient quality for repacking and further sale; and when there is return of some products that are already deteriorated. While in the reverse logistics literature remanufacturing is typically related to product returns (Krikke, le Blanc and van de Velde, 2004; Guide and Van Wassenhove, 2009), and the operation typically takes place at the manufacturer of the parts or components (Quariguasi Frota Neto et al., 2010; Rahman, 2012), in fresh food supply chains, remanufacturing can take place at processors, wholesalers and retailers (see figures 2, 3 and 4).

Now we discuss propositions related to remanufacturing.

Proposition 1a: Financial value from recovery is a necessary condition for profitability of companies engaged in remanufacturing, but not for an occurrence of the 'remanufacturing' loop itself. 
Table 4. Remanufacturing flows

\begin{tabular}{|c|c|c|c|c|c|c|}
\hline Network & $\begin{array}{l}\text { Product residual } \\
\text { value }\end{array}$ & Quantity & Market & Value & Profitability & $\begin{array}{l}\text { Circular } \\
\text { flow }\end{array}$ \\
\hline A & High & High & Open & $\overline{F(+)}$ & Yes & Yes \\
\hline B & High & High & No & F (-) & No & Yes \\
\hline $\mathrm{C}$ & High & High & No & No & No & No \\
\hline \multirow[t]{3}{*}{$\mathrm{A}$} & \multirow[t]{3}{*}{ High } & \multirow[t]{3}{*}{ Low } & Open & $\mathrm{F}(++)$ & Yes & Yes \\
\hline & & & Closed & $\mathrm{F}(++)$ & Yes & Yes \\
\hline & & & No* & F (-) & No & $\mathrm{No}^{*}$ \\
\hline B & High & Low & No* & F (-) & No & No* \\
\hline \multirow[t]{2}{*}{$\mathrm{C}$} & \multirow[t]{2}{*}{ High } & \multirow[t]{2}{*}{ Low } & Closed & $\mathrm{F}(+)$ & Yes & Yes \\
\hline & & & $\mathrm{No}^{*}$ & F (-) & No & $\mathrm{No}^{*}$ \\
\hline A & Low & High & No & No & No & No \\
\hline B & Low & High & No & No & No & No \\
\hline $\mathrm{C}$ & Low & High & Open & $\mathrm{F}(++)$ & Yes & Yes \\
\hline $\mathrm{A}$ & Low & Low & No & No & No & No \\
\hline B & Low & Low & No & No & No & No \\
\hline $\mathrm{C}$ & Low & Low & Open & $\mathrm{F}(+)$ & Yes & Yes \\
\hline
\end{tabular}

Legend: F - Financial value; (++) significant; (+) small; (-) financial loss; S - Social value; * - backorders due to commercial return; Grey fields: Significant remanufacturing flows

As Table 4 shows, economic value is a necessary condition for profitability of a company engaged in value recovery operations: in all instances where value from recovery operations is positive, there is profitability of the operation and vice versa. 
As observed in network A, the wholesaler remanufactures high residual value products and achieves profitability by 1) cost reduction and use of economy of scale, 2) higher productivity due to routine, fast operations and 3) revenue from sale of mixed, customised packages. Similar to findings of de Koster, de Brito and van de Vendel, (2002) and Stock and Mulki, (2009), remanufacturing occurs in a designated, large part of the warehouse. Though this type of remanufacturing does not require specialised equipment, it does require skilled and trained workers (Ferrer and Whybark, 2000) to correctly estimate changing product residual value. Many workers in this sector are temporary (Spence and Bourlakis, 2009), and the lack of available labour can affect the feasibility of remanufacturing operations, i.e. it is a potential barrier to the creation of circular flows.

As economies of scale reduce re-manufacturing costs (Guide and Van Wassenhove, 2009), it is expected that remanufacturing would appear only when quantities are sufficient. However, in food networks, small scale, specific remanufacturing operations also take place on high residual value products. In common with the strategy used by large retailers (Holweg, Teller, and Kotzab, 2016), fresh products are prepared and sold in the retailer's cafes in network C. As observed in network A, small, experienced retailers that have trained staff and available space (Stock and Mulki, 2009) upcycle products identified as "in risk of waste" (perishable and slow inventory rotation products, and products with early signs of damage) and, thus, also reduce risks of food waste. This runs counter to expectations as SMEs are less likely to manage risks associated with food recovery (Vlajic, 2016) and customer perceptions of recovered products (Tsiros and Heilman, 2005).

Though products with low residual value are generally not used as recovery costs would be higher than recovered value (Guide and Van Wassenhove, 2009), there 
are exceptions in food supply chains. A processor in network $\mathrm{C}$ conducts large scale manufacturing and remanufacturing operations for fresh products rejected from the forward flow due to strict specifications of the key customer (Garrone, Melacini and Perego, 2014). As the technical manager of a processor in network C states: "[products] might differ only in size from first class products, or might have a damaged part or blemishes on the surface". Due to centralised operations and the high quantity being recovered they can achieve economy of scale in processing (Rogers and Tibben $\square$ Lembke, 2001), and even perform more profitable operations by upcycling recovered products (e.g. production of prepared vegetables), as typically done in the textile and electronic industries (Dervojeda et al., 2014; Webster, 2015). In contrast to other processors in networks $\mathrm{A}$ and $\mathrm{B}$, this processor, as a mid-size company, was able to invest into specialised equipment to achieve a large-scale operation. This is common in networks of large retailers, which form strategic alliances with their suppliers (White, 2000; Hingley, 2005).

Table 4 (column 'Circular flow') shows that remanufacturing loops exist even in instances of non-profitability of an operation for the company, as found at wholesalers in all networks. This is a consequence of backorders after commercial returns: "it cost us about $£ 19$ to do every delivery to correct mistakes of product return, and it can go up to $£ 300$ a day" (managing director of wholesale in network A). Remanufacturing in wholesale is very labor intensive and expensive (c.f. van der Vorst, 2000): the wholesaler in network B estimated the cost of recovery to be higher than the recovered product value, and therefore unprofitable, so that despite there being sufficient quantities remanufacturing takes place only when necessary (e.g. during inventory shortages). 
Proposition 2b: Remanufacturing loop typically feeds into primary markets in fresh food supply chains.

As Table 4 (column 'market') shows, in fresh food supply chains remanufactured products are typically sold in alternative markets. Again, this contradicts Beamon and Fernandes (2004) and Rahman and Subramanian (2012). Similarly, in the case of reuse (see Section 5.1, reselling), due to fast deterioration (Blackburn et al., 2004) products require fast re-processing or repacking. They often cannot be sold to key customers (wholesalers or retailers) due to lack of sufficient quantity or poorer quality than required.

As found at the retailers in networks $\mathrm{A}$ and $\mathrm{C}$, the creation of closed loops occurs when the remanufactured products are sold to primary customers together with the service (e.g. ready meals served in supermarket's cafes,), or when products are upcycled at retailers (Holweg, Teller, and Kotzab, 2016).

\section{3. 'Recycle' as value recovery process}

Proposition 1c: Financial value from recovery is a necessary condition for profitability of a company engaged in recycling, but not for an occurrence of the 'recycling' loop itself.

As Table 5 shows, financial value is a necessary condition for profitability of a company engaged in value recovery operations. Where financial value from recycling is positive, profitability results and vice versa. Table 5, column 'Quantity', shows that in line with Fleischmann et al. (2005), profitability in recycling results from large scale recycling operations. In network $\mathrm{C}$ both the processor and the large retailer collect high quantities of low residual value from upstream and downstream networks respectively. This results in energy recovery (Giugliano et al., 2011): "Last year we had more than 98\% of products diverted from the landfill and recovered around 8\% of energy", 
(Corporate Affairs Manager, retailer, network C). Similar to methods used by Dutch supermarkets (de Koster, de Brito and van de Vendel, 2002), all food designated for recycling is centrally collected at the RDC to reduce costs. A processor in network C uses a similar strategy: Unsaleable products and by-products from processing activities are recycled by anaerobic digestion. The General Manager (processor in network C) states: "what's not saleable in terms of rotten or defects,... skins, cuts or tops and tails, all go into the anaerobic digester which then makes electricity. In a year, we use about 15,000 tonnes of vegetables, grass and maize in the digester and it produces enough electricity for the company, ... and we also send excess back to the grid."

Table 5 also shows (column 'Circular flow') that circular loops exist even in instances of non-profitability. As there is are no economies of scale, recycling of low residual value products is conducted 1) internally, in closed loops in all three upstream parts of the networks, in situations such as crop failure or damage through bad weather or during the harvest (Vlachos, 2015); 2) in open loops, in downstream networks A and B due to legislative requirements for businesses introduced by the regional Environmental Agency. (From April $1^{\text {st }} 2017$ all food businesses that generate more than $5 \mathrm{~kg}$ of food waste have to separate it and arrange for its collection or comply to the collection scheme). 
Table 5. Recycling flows

\begin{tabular}{|l|l|l|l|l|l|l|}
\hline Network & Product & Quantity & Market & Value & Profitability & Circular \\
\hline A & High & High & No & No & No & flow \\
\hline B & High & High & No & No & No & No \\
\hline C & High & High & No & No & No & No \\
\hline A & High & Low & Closed & F (-), N & No & Yes \\
\hline C & High & Low & No & No & No & No \\
\hline A & Low & Low & No & No & No & No \\
\hline B & Low & High & No* & F (--) & No & Yes* \\
\hline C & Low & High & No* & F (--) & No & Yes* \\
\hline A & Low & Low & Open & F (-), R & No & Yes \\
\hline & Low & Low & Closed & N & No & Yes \\
\hline & Low & Low & Open & F (-), R & No & Yes \\
\hline
\end{tabular}

Legend: F - Financial value; (++) significant; (+) small; (-) financial loss; S - Social value; N - Environmental value; $\mathrm{R}$ - regulations; Grey fields: Significant recycling flows; * - commercial return and administrative return

Proposition 2c: Recycling loop typically feeds into alternative markets in fresh food supply chains.

Beamon and Fernandes, (2004) and Rahman and Subramanian (2012) suggest that recycling typically takes part in open loop supply chains, performed by large-scale 
specialists (Rogers and Tibben-Lembke, 2001). However, Table 5 (column 'Market') and Figure 5 show that in fresh food supply chains, recycling appears more likely as part of a closed loop system. This can be explained by the size of the companies and the ease of collecting material for recycling: Large and medium size companies have enough resources to organise and manage recycling operations and the potential to reduce energy consumption (Bourlakis et al., 2014), as shown in the network $\mathrm{C}$, but not in networks $\mathrm{A}$ and $\mathrm{B}$. In network $\mathrm{C}$, both processor and retailer have established routes for the efficient collection of material for recycling: The processor collects rejected material from the processing lines, as well as low residual value products from its supply network, while the retailer collects out-of-date products from outlets and RDC. It is likely that the vertical integration at processors (production and processing) and in the retail system (distribution, retail and recycling), as well as strategic alliance between companies in network $\mathrm{C}$ enables the centralisation of operations and results in economies of scale (Fleischman et al., 2005). In SME networks, characterised by decentralised recovery operations, recycling is part of both, open loops (e.g. use of public recycling centres) as well as closed loops (e.g. recycling at the production site).

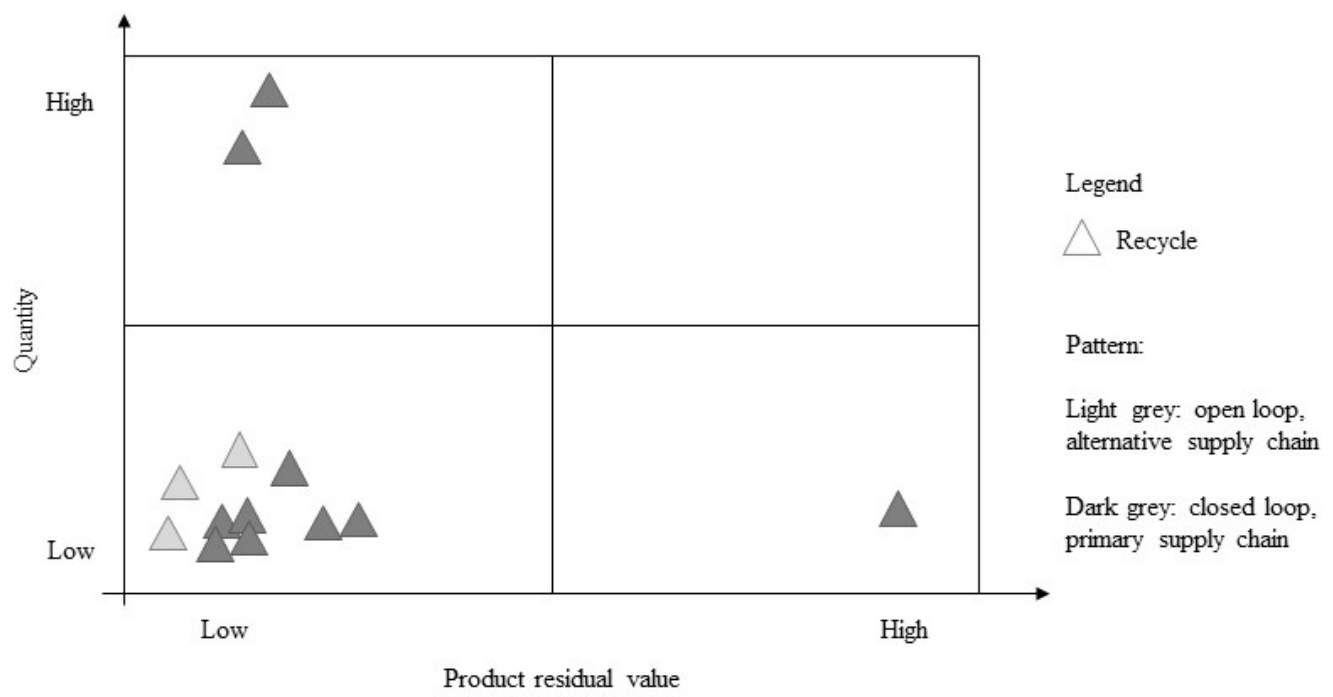

Figure 5. Value recovery via recycling in networks A, B and C 


\section{Conclusion}

In response to calls for empirical research on reverse logistics (Stock and Mulki, 2009) and developing theory on circular supply chains (Nasir et al., 2017; Weetman, 2017), we 1) defined circular supply chains in the context of value recovery processes and critical elements for product recovery, and 2) analysed and discussed value recovery processes and circular flows in fresh food supply chains by testing how critical factors affect circular flows. In our study, we used theories developed in the literature on reverse logistic and closed-loop supply chains, food waste management, food supply chains, and circular supply chains.

Based on these insights, we defined circular supply chains in the context of value recovery, and considered circular flows as the integration of forward and reverse loops. We now summarise our key findings to theory on circular supply chains, and particularly to theory on fresh food supply chains.

The main contributions to the theory of supply chain management, reverse logistics and circular economy of our study are the following:

First, we show that value recovery processes are integral part of circular flows in food supply chains. By investigating each recovery process separately, we confirm empirically that financial value from recovery is not a necessary condition for the creation of a circular flow in food supply chains. Circular flows might occur in any combination of product residual value and quantity that enters such value recovery processes.

Second, we show that circular food supply chains are specific with regard to the market for recovered products: While the theory on closed-loop supply chains suggests that reuse and remanufacturing flows typically feed back into the primary chain, via 
closed-loops, we found the opposite in fresh food supply chains. Also, recycling flows do not feed into alternative markets, but likely feed back into primary chain. Hence, as Stock and Mulki (2009) suggest, findings on reverse flows are industry specific.

Third, we confirm proposition 3 in the context of fresh food supply chains (Figure 6): The higher the residual value of the product, the more likely the higher value recovery process will be chosen. Large quantities of high residual value products are indeed part of 'Reuse' recovery processes, as is typical for large and medium size companies, and are found in all networks with larger companies upstream (Tromp et al., 2016). However, there are two exceptions.

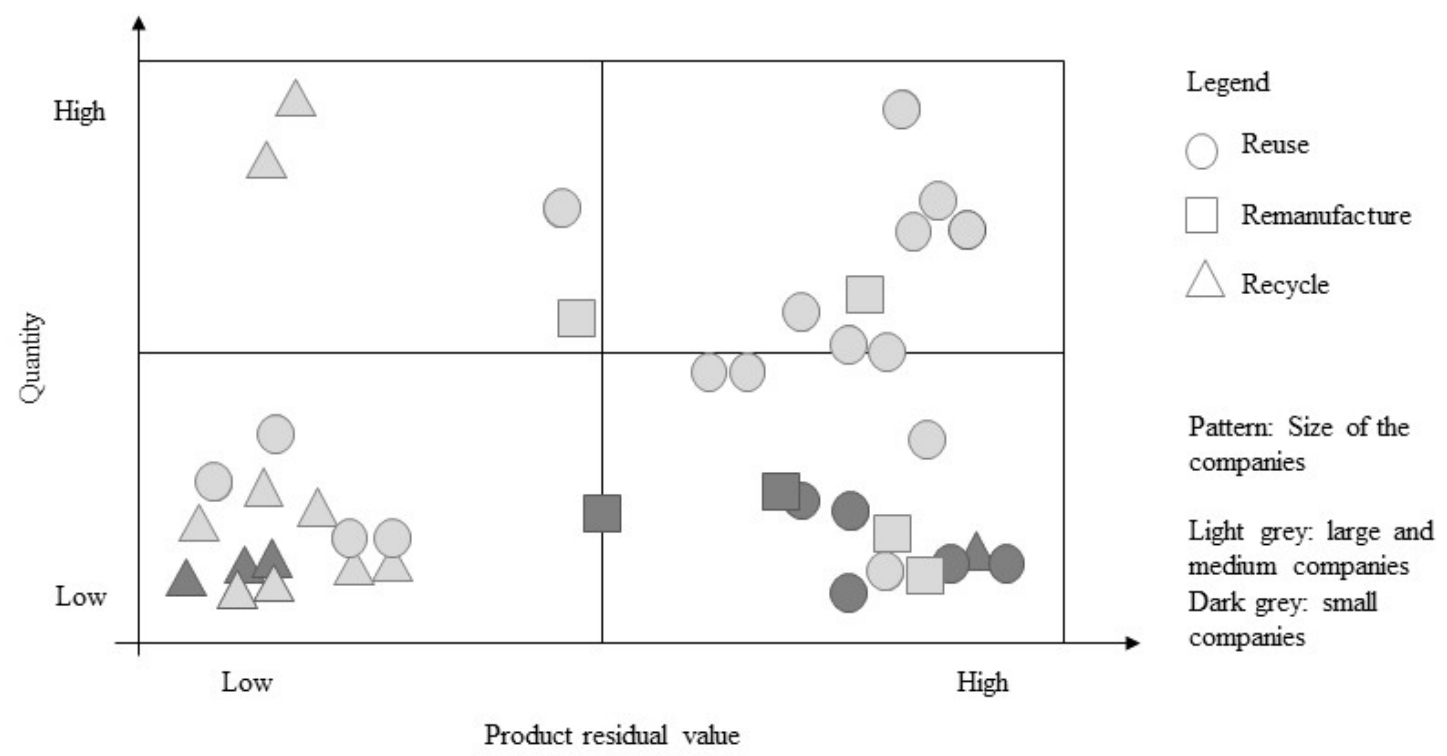

Figure 6. Value recovery processes in relation to the product residual value and quantity

The first exception is found in the case of international suppliers, when received products are of heterogeneous quality. As return is uncommon, there is a need for sorting, re-packing or re-processing. A second exception concerns the small quantities of high residual value products, which are rarely resold by smaller companies due to fear of reputational damage in their small, known customer base (Bourlakis et al., 2014). Thus, they upcycle products (see section 5.3) and sell them to primary or 
alternative customers or exceptionally for producers, recycle these products - this occurs in situations of increased yield and lack of demand. The literature confirms this as the main practice of small food producers, which 1) tend to focus on production activities, and leave sales and marketing activities to middlemen and traders (Parfitt et al., 2010), and 2) do not have adequate resources (Arend and Wisner, 2005) (e.g. cold storage for very perishable products).

Fourth, we included re-manufacturing in the study of the fresh food supply chain. Though recovery processes are considered in multiple studies about food waste, remanufacturing did not receive sufficient attention in the literature on waste management, and reverse logistics/closed-loop supply chain. We offer specific insights on remanufacturing in the context of SMEs and food supply chains.

Fifth, we contribute to the methodology on data collection and validation for circular flows: Data for each case analysed is double verified, from the input and output side, i.e. supply and demand side of the company. These kinds of studies are rare in the supply chain literature, where most of the papers investigate dyadic relationships (Harland, Lamming and Cousins, 1999) in the case study settings (e.g. Matopoulos et al., 2007). This methodology is limited by the sparseness of the quantitative data: Quantities, costs and profits are estimated as averages by the interviewees. Availability of additional quantitative data would enable the development of mathematical or simulation models for better estimations of achieved values from recovery.

Our findings are limited to fresh food supply chains, and additional research is needed to extend it to the entire food sector. Additionally, circular flows in FSCs differ between countries due to legislation on food trade and food safety, customer preferences, expected value from recovery and environmental conditions. As our findings are based on business practices in a region of a developed country in a specific 
climate zone, future research should address the impact of these factors to management of circular FSCs.

Additionally, our study does not include resource reduction, as this is not a value recovery process. However, resource reduction is important for circular supply chains. This is the topic of numerous studies focused on new technologies, eco-design, use of scale and efficient use of existing resources (Chopra and Meindl, 2013). However, there is only a small number of studies that holistically analyse effects of value recovery processes on resource reduction.

\section{Acknowledgement}

This work is supported by the Centre for Irish Business and Economic Performance, Queen's University Belfast (QUB) under grant for the project: “Waste Not, Want Not: Contributing to a Sustainable Food Industry by Managing Food Waste We would also like to thank Belfast Food Network, the Science Shop at QUB and companies which supported this research by granting us interviews and allowing observation of their work.

\section{References}

1. Alexander, C., and C. Smaje. 2008. "Surplus retail food redistribution: An analysis of a third model.” Resources, Conservation and Recycling 52 (11): 12901298. doi: 10.1016/j.resconrec.2008.07.009.

2. Arend, R.J., and J.D. Wisner. 2005. "Small business and supply chain management: is there a fit?" Journal of Business Venturing, 20: 403-436. doi: 10.1016/j.jbusvent.2003.11.003. 
3. Atasu, A., V.D.R. Guide, Jr., and L.N. van Wassenhove. 2008. "Product Reuse Economics in Closed-Loop Supply Chain Research.”, Production and Operations Management, 17(5): 483-496. doi: 10.3401/poms.1080.0051.

4. Autry, C.W., P.J. Daugherty and R.G. Richey. 2001. "The Challenge of Reverse Logistics in Catalog Retailing.”, International Journal of Physical Distribution and Logistics Management 31 (1): 26-37. doi: 10.1108/09600030110366384.

5. Beamon, B.M., and C. Fernandes. 2004. "Supply-chain network configuration for product recovery." Production Planning and Control 15(3): 270-281. doi: $10.1080 / 09537280410001697701$.

6. Beh, L.S., A. Ghobadian, Q. He, D. Gallear, and N. O'Regan. 2016. “Second-life retailing: a reverse supply chain perspective.” Supply Chain Management: An International Journal, 21(2): 259-272. doi: 10.1108/SCM-07-2015-0296.

7. Blackburn, J.D., V.D.R. Guide, Jr., G.C. Souza and L.N. van Wassenhove. 2004. “Reverse supply chains for commercial returns.”, California Management Review, 46(2): 6-22. DOI: 10.2307/41166207.

8. Blackburn, J.D., and G.D. Scudder. 2009. "Supply Chain Strategies for Perishable Products: The Case of Fresh Produce.” Production and Operations Management 18(2): 129-137. doi: 10.1111/j.1937-5956.2009.01016.x.

9. Boulding, K.E. 1966. "The Economics of the Coming Spaceship Earth". In Environmental Quality in Growing Economy. Resources for the Future. Washinton DC. doi: 10.4324/9781315064147.

10. Braungart, M., and W. McDonough. 2009. Cradle to Cradle. Remaking the Way We Make Things. London: Vintage Books.

11. Bourlakis, M., G. Maglaras, E. Aktas, D. Gallear and C. Fotopoulos. 2014. "Firm size and sustainable performance in food supply chains: Insights from Greek 
SMEs.” International Journal of Production Economics 152: 112-130. doi: 10.1016/j.ijpe.2013.12.029.

12. Carter, C.R., and L.M. Ellram. 1998. "Reverse Logistics: A Review of the Literature and Framework for Future Investigation.” Journal of Business Logistics 19(1): 85-102.

13. Chertow, M., 2007. ““Uncovering” Industrial Symbiosis”, Journal of Industrial Ecology 11(1): 11-30. DOI: 10.1162/jiec.2007.1110.

14. Chopra, S., and P. Meindl. 2013. Supply Chain Management. Strategy, Planning, and Operation. Boston: Pearson.

15. Christopher, M., 2011. Logistics and Supply Chain Management. Harlow: Financial Times Prentice Hall.

16. Daaboul, J., J. Le Duigou, D. Penciuc, and B. Eynard. 2016. “An integrated closed-loop product lifecycle management approach for reverse logistics design.” Production Planning \& Control 27(13): 1062-1077. doi: 10.1080/09537287.2016.1177234

17. de Brito, M. and R. Dekker. 2002. Reverse logistics-a framework. Econometric Institute Report. EI 2002, 38, pp. 1-19.

18. de Koster, R.B.M., M.P. de Brito, René BM, and M.A. van de Vendel. 2002. "Return handling: an exploratory study with nine retailer warehouses."International Journal of Retail \& Distribution Management 30(8): 407-421. doi: 10.1108/09590550210435291.

19. DEFRA. 2011. Guidance on the application of date labels to food. Sept. 2011, Department for environment, Food and Rural Affairs and Food Standards Agency. 
20. Despeisse, M., F. Mbaye, P.D. Ball, and A. Levers. 2012. "The emergence of sustainable manufacturing practices." Production Planning \& Control 23(5): 354376. doi: 10.1080/09537287.2011.555425.

21. Dervojeda, K., D. Verzijl, E. Rouwmaat, L. Probst, and L. Frideres. 2014. Clean Technologies, Circular supply chains. The report produced by Business Innovation Observatory, Contract No 190/PP/ENT/CIP/12/C/N03C01, European Union.

22. Dowlatshahi, S. 2000. "Developing a theory of reverse logistics." Interfaces 30(3): 143-155. doi: 10.1287/inte.30.3.143.11670.

23. Eisenhardt, K. M. 1989. "Building theories from case study research." Academy of management review 14(4): 532-550. doi: 10.2307/258557.

24. European Commission. 2005. The New SME Definition: User Guide and Model Declaration. Luxembourg: European Commission Publications Office.

25. European Commission 2010. Preparatory study on food waste across EU 27. Technical report - 2010 - 054. DOI : 10.2779/85947

26. European Commission Agriculture and Rural Development. 2011. What is a small farm? EU Agricultural Economic Briefs, Brief No 2-July 2011.

27. FAO 2012. The State of Food Insecurity in the World 2012. Food and Agriculture Organization of the United Nations, Rome.

28. Ferguson, N., and J. Browne. 2001. "Issues in end-of-life product recovery and reverse logistics." Production Planning and Control 12(5): 534-547. doi: 10.1080/0953728011004288.

29. Ferguson, M., and M.E. Ketzenberg. 2006. "Information sharing to improve retail product freshness of perishables." Production and Operations Management 15(1): $57-73$. 
30. Ferrer, G., and D.C. Whybark. 2000. "From Garbage to Goods: Successful Remanufacturing Systems and Skills.”, Business Horizons, 55-64. doi: 10.1016/S0007-6813(00)80023-3.

31. Fleischmann, M., J. van Nunen, B. Grave and R. Gapp. 2005. "Reverse Logistics - Capturing Value in the Extended Supply Chain.” In Supply Chain Management on Demand, edited by An, C., and H. Fromm, 167-186. Berlin: Springer.

32. Garetti, M., and Taisch, M., 2012. "Sustainable manufacturing: trends and research challenges." Production Planning and Control 23 (2-3): 83-104. doi: $10.1080 / 09537287.2011 .591619$.

33. Garrone, P., M. Melacini, and A. Perego. 2014. "Opening the black box of food waste reduction." Food Policy 46: 129-139. doi: 10.1016/j.foodpol.2014.03.014.

34. Geng, Y., and B. Doberstein. 2008. "Developing the circular economy in China: Challenges and opportunities for achieving 'leapfrog development'." International Journal of Sustainable Development and World Ecology 15: 231239. doi: 10.3843/SusDev.15.3.

35. Genovese, A., A.A. Acquaye, A. Figueroa, and S.C L. Koh. 2017. "Sustainable supply chain management and the transition towards a circular economy: Evidence and some applications." Omega, 66: 344-357. doi: 10.1016/j.omega.2015.05.015.

36. Gharfalkar, M., R. Court, C. Campbell, Z. Ali and G. Hiller. 2015. "Analysis of waste hierarchy in the European waste directive 2008/98/EC." Waste management 39: 305-313. doi: 10.1016/j.wasman.2015.02.007.

37. Gibbert, M., W. Ruigrok and B. Wicki. 2008. "What passes as a rigorous case study?" Strategic management journal 29(13): 1465-1474. doi: 10.1002/nml. 
38. Giuseppe A., E. Mario and M. Cinzia. 2014. "Economic benefits from food recovery at the retail stage: An application to Italian food chains." Waste Management 34: 1306-1316. doi: 10.1016/j.wasman.2014.02.018.

39. Govindan, K., and H. Soleimani. 2016. "A review of reverse logistics and closedloop supply chains: A Journal of Cleaner Production focus.” Journal of Cleaner Production, 142: 371-384. doi: 10.1016/j.jclepro.2016.03.126.

40. Gustavsson, J., Cederberg, C., Sonesson, U., van Otterdijk, R., Meybeck, A. 2011. Global Food Losses and Food Waste. Food and Agriculture Organization of the United Nations, FAO, Rome.

41. Gobbi, C., 2011. "Designing the reverse supply chain: the impact of the product residual value.” International Journal of Physical Distribution \& Logistics Management 41(8): 768-796. doi: 10.1108/09600031111166429.

42. Guide Jr, V.D.R., and L.N. Van Wassenhove. 2009. “The evolution of closed-loop supply chain research." Operations research 57(1): 10-18. doi.org/10.1287/opre.1080.0628.

43. Hahn, K.H., H. Hwang and S.W. Shinn. 2004. "A returns policy for distribution channel coordination of perishable items." European Journal of Operational Research 152: 770-780. doi: 10.1016/S0377-2217(02)00753-1.

44. Hamister, J.W., and N.C. Suresh. 2008. "The impact of pricing policy on sales variability in a supermarket retail context.", International Journal of Production Economics 111: 441-455. doi: 10.1016/j.ijpe.2007.01.011.

45. Harland, C.M., R.C. Lamming, and P.D. Cousins. 1999. "Developing the concept of supply strategy." International Journal of Operations \& Production Management 19(7) (1999): 650-674. doi: 10.1108/01443579910278910. 
46. Henson, S,. and T. Reardon. 2005. "Private agri-food standards: Implications for food policy and the agri-food system." Food policy 30(3): 241-253. doi: 10.1016/j.foodpol.2005.05.002.

47. Hingley, M.K. 2005. "Power imbalance in UK agri-food supply channels: Learning to live with the supermarkets?" Journal of Marketing Management 21(12): 63-88. doi: 10.1362/0267257053166758.

48. Holweg, C., E. Lienbacher and W. Zinn. 2011. "Social supermarkets: a new challenge in supply chain management and sustainability." Supply Chain Forum: An International Journal 11(4): 50-59.

49. Holweg, C., C. Teller, and H. Kotzab. 2016. "Unsaleable grocery products, their residual value and instore logistics." International Journal of Physical Distribution \& Logistics Management 46, 6/7: 634-658. doi: DOI 10.1108/IJPDLM-05-2013-0155.

50. Huge Brodin, M., and H. Anderson. 2008. "Recycling calls for revaluation."Supply Chain Management: An International Journal 13(1): 9-15. doi.org/10.1108/13598540810850274.

51. Jayaraman, V., and Y. Luo. 2007. "Creating Competitive Advantages Through New Value Creation: A Reverse Logistics Perspective.”, Academy of Management Perspectives, 21(2): 56-73. doi: 10.5465/amp.2007.25356512.

52. Jones, P., D. Comfort, and D. Hillier. 2004. "A case study of local food and its routes to market in the UK." British Food Journal, 106(4): 328-335. doi: 10.1108/00070700410529582.

53. Lambert, D.M.,and M.C. Cooper. 2000. "Issues in Supply Chain Management", Industrial Marketing Management 29: 65-83. doi: 10.1016/S00198501(99)00113-3. 
54. Kenne, J.P., Dejax, P. and Gharbi, A. 2012. Production planning of a hybrid manufacturing-remanufacturing system under uncertainty within a closed-loop supply chain. International Journal of Production Economics, 135(1), pp.81-93. doi.org/10.1016/j.ijpe.2010.10.026

55. Krikke, H., I. le Blanc, and S. van de Velde. 2004. "Product modularity and the design of closed-loop supply chains." California management review 46(2): 2339.

56. Krikke, H., J.A.E.E. van Nunen, R. Zuidwijk, R. Kuik. 2005. "E-business and Circular Supply Chains: Increased Business Opportunities by IT-based Customer Oriented Return-flow Management. In Distribution Logistics, Edited by Fleischmann, B. and A. Klose, 221-239. Berlin, Heidelberg: Springer.

57. Kumar, S. and P. Malegeant. 2006. "Strategic alliance in a closed-loop supply chain, a case of manufacturer and eco-non-profit organization.” Technovation 26(10): 1127-1135. DOI: 10.1016/j.technovation.2005.08.002

58. Kumar, S., and V. Putnam. 2008. "Cradle to cradle: Reverse logistics strategies and opportunities across three industry sectors." International Journal of Production Economics 115(2): 305-315. doi.org/10.1016/j.ijpe.2007.11.015

59. Lieder, M., and A. Rashid. 2016. "Towards circular economy implementation: A comprenhensive review in context of manufacturing industry" Journal of Cleaner Production 115: 36-51. doi: 10.1016/j.jclepro.2015.12.042.

60. Lincoln, Y.S. 1995. "Emerging criteria for quality in qualitative and interpretive research." Qualitative inquiry 1(3): 275-289.

61. Linton, J. D., R. Klassen, and V. Jayaraman. 2007. "Sustainable supply chains: An introduction." Journal of operations management 25(6): 1075-1082. doi: 10.1016/j.jom.2007.01.012. 
62. Liu, G., J. Zhang and W. Tang. 2015. "Joint dynamic pricing and investment strategy for perishable foods with price-quality dependent demand.", Annals of Operations Research 226: 397-416. doi: 10.1007/s10479-014-1671-x.

63. Matopoulos, A., M. Vlachopoulou, V. Manthou, and B. Manos. 2007. “A conceptual framework for supply chain collaboration: empirical evidence from the agri-food industry." Supply Chain Management: An International Journal 12(3): 177-186. doi: 10.1108/13598540710742491.

64. Mena, C., B. Adenso-Diaz and O. Yurt. 2011 "The causes of food waste in the supplier-retailer interface: Evidences from the UK and Spain.” Resources, Conservation and Recycling 55: 648-658. doi: 10.1016/j.resconrec.2010.09.006.

65. Mena, C., L.A. Terry, A. Williams, L. Ellram. 2014. "Causes of waste across multi-tier supply networks: Cases in the UK food sector." International Journal of Production Economics 152: 144-158. doi: 10.1016/j.ijpe.2014.03.012.

66. Miemczyk, J., M. Howard, T.E. Johnsen. 2016. "Dynamic development and execution of closed-loop supply chains: a natural resource-based view.” Supply Chain Management: An International Journal 21(4): 453-469. doi: 10.1108/SCM-12-2014-0405.

67. Miles, M.B., A.M. Huberman, J. Saldana. 2014. Qualitative Data Analysis. A Methods Sourcebook. Third edition, Los Angeles: Sage.

68. Mirabella, N., V. Casteallani, and S. Sala. 2014. "Current options for the valorization of food manufacturing waste: a review." Journal of Cleaner Production 65: 28-41. doi: 10.1016/j.jclepro.2013.10.051.

69. Mourad, M. 2016. "Recycling, recovering and preventing "food waste": competing solutions for food systems sustainability in the United States and 
France.” Journal of Cleaner Production 126: 461-477. doi:

10.1016/j.jclepro.2016.03.084.

70. Mulhern, F.J., and D.T. Padgett. 1995. "The Relationship between retail price promotions and regular price purchases.” Journal of Marketing 59: 83-90.

71. Oglethorpe, D., and G. Heron. 2013. "Testing the theory of constraints in UK local food supply chains.", International Journal of Operations and Production Management, 33(10): 1346-1367. doi: 10.1108/IJOPM-05-2011-0192.

72. Papargyropoulou, E., R. Lozano, J.K. Steinberger, and N. Wright, 2014. “The food waste hierarchy as a framework for the management of food surplus and food waste.” Journal of Cleaner Production 76: 106-115. doi:

10.1016/j.jclepro.2014.04.020.

73. Parfitt, J., M. Barthel, and S. Macnaughton. 2010. "Food waste within food supply chains: quantification and potential for change to 2050." Philosophical Transactions of The Royal Society B 365: 3065-3081. doi:

10.1098/rstb.2010.0126.

74. Quariguasi Frota Neto, J., G. Walther, J. Bloemhof, J.A.E.E. van Nunen and T. Spengler (2010). "From closed-loop to sustainable supply chains: the WEEE case.” International Journal of Production Research 48(15): 4463-4481. doi: 10.1080/00207540902906151.

75. Rahman, S. 2012. "Reverse Logistics”, In Global Logistics and Supply Chain Management. Edited by Mangan, J., C. Lalwani, T. Butcher, and R. Javadpour, 338-353. Chichester: John Wiley and Sons.

76. Rahman, S., and Subramanian, N. 2012. "Factors for implementing end-of-life computer recycling operations in reverse supply chains.", International Journal of Production Economics, 140: 239-248. doi: 10.1016/j.ijpe.2011.07.019. 
77. Rogers, D.S., and R. Tibben $\square$ Lembke. 2001. “An examination of reverse logistics practices.” Journal of business logistics 22(2): 129-148. DOI: 10.1002/j.21581592.2001.tb00007.x

78. Seuring, S. 2008. "Assessing the rigor of case study research in supply chain management.”, Supply Chain Management: An International Journal 13(2): 128137. doi: $10.1108 / 13598540810860967$.

79. Sgarbossa, F. and I. Russo. 2017. “A proactive model in sustainable food supply chain: Insights from a case study.", International Journal of Production Economics 183: 596-606. doi: 10.1016/j.ijpe.2016.07.022.

80. Simchi-Levi, D., P. Kaminsky, and E. Simchi-Levi. 2008. Designing and Managing the Supply Chain: Concepts, Strategies, and Case Studies. New York: McGraw-Hill Irwin.

81. Slack, N., A. Brandon-Jones and R. Johnston. 2013. Operations Management. Edinburgh: Pearson Education Limited.

82. Spence, L., and M. Bourlakis, 2009. "The evolution from corporate social responsibility to supply chain responsibility: the case of Waitrose.” Supply Chain Management: An International Journal 14(4): 291-302. doi.org/10.1108/13598540910970126

83. Stahel, W.R. 2006. The Performance Economy. Palgrave Macmillan.

84. Stenmarck, A., O.J.Hanssen, K. Silvennoinen, J-M. Katajajuuri, M. Werge. 2011. Initiatives on prevention of food waste in the retail and wholesale trades. TemaNord, Nordic Council of Ministers, Copenhagen.

85. Stock, J.R., and J.P. Mulki. 2009. "Product returns processing: An examination of practices of manufacturers, wholesalers/distributors, and retailers." Journal of Business Logistics 30(1): 33-62. doi: 10.1002/j.2158-1592.2009.tb00098.x. 
86. Su, B., A. Heshmati, Y. Geng, and X. Yu. 2013. "A review of the circular economy in China: moving from rhetoric to implementation." Journal of Cleaner Production 42: 215-227. doi: 10.1016/j.jclepro.2012.11.020.

87. Tibben-Lembke, R.S. 2002. "Life after death: reverse logistics and the product life cycle." International Journal of Physical Distribution and Logistics Management 32(3): 223-244. doi.org/10.1108/09600030210426548.

88. Tibben-Lembke, R.S. 2004. "Strategic use of the secondary market for retail consumer goods.” California Management Review 46(2):90-104. DOI: $10.2307 / 41166212$

89. Tibben-Lembke, R.D., and D.S. Rogers. 2002. "Differences between forward and reverse logistics in a retail environment." Supply Chain Management: An International Journal 7(5): 271-282. doi: 10.1108/13598540210447719.

90. Thierry, M., M. Salomon, J. Van Nunen, and L. Van Wassenhove. 1995. "Strategic issues in product recovery management." California management review 37(2): 114-135. DOI: 10.2307/41165792.

91. Thyberg, K.L., and D.J. Tonjes. 2016. "Drivers of food waste and their implications for sustainable policy development." Resources, Conservation and Recycling 106: 110-123. doi: 10.1016/j.resconrec.2015.11.016.

92. Tromp, S.-O., R. Haijema, H. Rijgersberg, and J.G.A.J. van der Vorst. 2016. “A systematic approach to preventing chilled-food waste at the retail outlet." International Journal of Production Economics 182: 508-518. doi: 10.1016/j.ijpe.2016.10.003.

93. Tsiros, M., and Heilman, C.M. 2005. "The Effect of Expiration Dates and Perceived Risk on Purchasing Behaviour in Grocery Store Perishable Categories." Journal of Marketing 69: 114-129. 
94. Tsoulfas, G.T., and C.P. Pappis. 2006. "Environmental principles applicable to supply chains design and operation." Journal of Cleaner Production 14: 15931602. doi: 10.1016/j.jclepro.2005.05.021.

95. Van der Vorst J.G.A.J. 2000. "Effective food supply chains, Generating, modelling and evaluating supply chain scenarios.” $\mathrm{PhD}$ dissertation, Wageningen University.

96. Van der Vorst, J., Beulens, A. and van Beek, P., 2005. "Innovations in logistics and ICT in food supply chain networks." In Innovation in agri-food systems: Product quality and consumer acceptance, p.245.

97. Vlachos, I. 2015. “Applying lean thinking in the food supply chains: a case study." Production Planning and Control 26 (16): 1351-1367. doi: 10.1080/09537287.2015.1049238.

98. Vlajic, J.V., M. Bogdanova and R. Mijailovic. 2016. "Waste Not, Want Not: Managing perishables in small and medium retail enterprises." $21^{\text {st }}$ International Symposium on Logistics, 3-6 ${ }^{\text {th }}$ July 2016: 330-340. Kaoshiung, Taiwan.

99. Vlajic, J.V. 2016. "Vulnerability and Robustness of SME Supply Chains: An Empirical Study of Risk and Disturbance Management of Fresh Food Processors in a Developing Market.” In Organizational Resilience: Concepts, Integration and Practice edited by Bhamra R. 86-102. CRC Press, Taylor and Francis.

100. Wang, X. and D. Li. 2012. “A dynamic product quality evaluation based pricing model for perishable food supply chains." Omega 40(6): 906-917. doi.org/10.1016/j.omega.2012.02.001

101. Webster, K. 2015. The Circular Economy, A Wealth of Flows. Cowes, UK: Ellen MacArthur Foundation Publishing. 
102. Weetman, C. 2017. A Circular Economy Handbook for Business and Supply Chains. Repair, Remake, Redesign, Rethink. New York: Kogan Page.

103. Wells, R. and M. Caraher. 2014. "UK print media coverage of the food bank phenomenon: from food welfare to food charity?” British Food Journal 116 (9): 1426-1445. doi: 10.1108/BFJ-03-2014-0123.

104. White, H.M.F. 2000. "Buyer-supplier relationship in the UK fresh produce industry." British Food Journal 102(1): 6-17. doi.org/10.1108/00070700010310605

105. Wilson, N., 1996. "The supply chains of perishable products in northern Europe.” British Food Journal, 98(6): 9-15. doi: 10.1108/00070709610131320.

106. http://webarchive.nationalarchives.gov.uk/20130123162956/http:/www.defra.gov. uk/evidence/statistics/foodfarm/farmmanage/fbs/documents/reference/farm_classi fication.pdf (accessed on 20 March 2016).

107. Yin, R.K. 1994. "Discovering the future of the case study method in evaluation research.” Evaluation Practice 15: 283-290. doi.org/10.1016/08861633(94)90023-X

108. Yin, R.K. 2014. Case Study Research. Design and Methods. Los Angeles: SAGE. 